NASA Technical Memorandum 101293

AIAA-88-3211

\title{
Performance and Lifetime Assessment of MPD Arc Thruster Technology
}

\author{
(NASA-TY-101293) PERFCRMANCE AND LIFETIME \\ A SSESSYENT OF MED AFC THEUSTEE THCHAOLCGY \\ $N 8 \mathcal{E}-2 S 860$ \\ (IASA) ¿S $\mathrm{F}$ \\ CSCL $21 \mathrm{H}$ \\ Unclas \\ $63 / 20 \quad 01655 \subseteq 7$
}

James S. Sovey and Maris A. Mantenieks

Lewis Research Center

Cleveland, Ohio

Presented at the

24th Joint Propulsion Conference

cosponsored by the AIAA, ASME, SAE, and ASEE

Boston, Massachusetts, July 11-13, 1988 


\title{
PERFORMANCE AND LIFETIME ASSESSMENT
}

OF MPD ARC THRUSTER TECHNOLOGY

\author{
James S. Sovey and Maris A. Mantenieks \\ National Aeronautics and Space Administration \\ Lewis Research Center \\ Cleveland, Ohio 44135
}

\begin{abstract}
SUMMARY
A summary of performance and lifetime characteristics of pulsed and steady-state magnetoplasmadynamic (MPD) thrusters is presented. The technical focus is on cargo vehicle propulsion for exploration-class missions to the Moon and Mars. Relatively high MPD thruster efficiencies of 0.43 and 0.69 have been reported at about 5000 s specific impulse using hydrogen and lithium, respectively. Efficiencies of 0.10 to 0.35 in the 1000 to $4500 \mathrm{~s}$ specific impulse range have been obtained with other propellants (e.g. Ar, $\mathrm{NH}_{3}$, $\mathrm{N}_{2}$ ). Thermal efficiency data in excess of 0.80 at MW power levels using pulsed thrusters indicate the potential of high MPD thruster performance. Extended tests of pulsed and steady-state MPD thrusters yield total impulses at least two to three orders of magnitude below that necessary for cargo vehicle propulsion. Performance tests and diagnostics for life-limiting mechanisms of megawatt-class thrusters will require high fidelity test stands which handle in excess of $10 \mathrm{kA}$ and a vacuum facility whose operational pressure is less than $3 \times 10^{-4}$ torr.
\end{abstract}

\section{INTRODUCTION}

The magnetoplasmadynamic (MPD) thruster system is an attractive candidate for lunar and Mars cargo vehicle propulsion as well as orbit raising applications. The high specific impulse (1000-5000 s) provided by the MPD thruster minimizes propellant requirements and improves the mass transfer capability to low-Earth-orbit (LEO). For example, Mars cargo vehicles using high performance chemical propulsion require propellant-to-total vehicle mass fractions of 0.7 to 0.8 as shown in figure 1 (ref. 1). Although aerobraking techniques might be employed at Mars and for Earth return to minimize total vehicle initial mass in LEO, the data of figure 1 indicate that the propellant is still approximately 70 percent of the initial mass.

In a different situation, shown in figure 2, a 180 metric ton payload can be delivered to Mars using a 5000 s specific impulse, 4 MW cargo vehicle employing electric propulsion with the required mass in LEO reduced by a factor of 1.9 compared to cryogenic chemical propulsion (ref. 2). In addition to the benefit of high specific impulse operation, the MPD thruster system may also yield lower total mission duration than encountered using chemical propulsion simply because of the time needed to accumulate additional propellant in LEO through multiple launches (ref. 3).

For the lunar and Mars cargo vehicle applications, the MPD thruster technology goals will need to include demonstrations of 0.1 to $10 \mathrm{MW}$ steady-state thrusters at thrust efficiencies in excess of 0.6 and 1 ifetimes in the 1000 to 
$10000 \mathrm{hr}$ range. Candidate propellants will probably include hydrogen as well as easily stored propellants such as ammonia, hydrazine, and argon. Scaling relations, performance limits, and lifetime projections of multimegawatt class MPD thrusters will have to be developed using quasi-steady state devices.

Given these preliminary technology goals, an assessment of the current state of MPD thruster technology related to performance and lifetime was undertaken.

This paper presents a summary of performance and lifetime generated by present generation MPD thrusters. Technological activities over the last 25 years will be briefly synopsized. Some of the basic thruster configurations will be described, and the effects of vacuum facility pressure on performance measurements will be discussed. Summary graphics describing operating modes, specific impulse, efficiency, thruster loss mechanisms, and demonstrated life will be presented. Prospects for improvements in specific impulse, efficiency, and life will also be discussed.

\section{NOMENCLATURE}

ho unheated propellant enthalpy, $\mathrm{kJ} / \mathrm{g}$

$I_{\text {sp }} \quad$ specific impulse, s

J arc current, $A$

$\left(\mathrm{J}^{2} / \dot{\mathrm{m}}\right)_{\mathrm{C}}$ onset parameter, $\mathrm{kA} \mathrm{A}^{2} \mathrm{~s} / \mathrm{g}$

$k \quad$ Boltzman's constant, $1.38 \times 10^{-23} \mathrm{~J} / \mathrm{K}$

m mass flow rate, $g / \mathrm{s}$

$P \quad$ input power, $\mathrm{kW}$

$\mathrm{Pe} \quad$ input electric power, $\mathrm{kW}$

$\mathrm{PL}_{\mathrm{L}} \quad$ power to water in arc-head assembly, $\mathrm{kW}$

$\mathrm{Pa}_{\mathrm{a}} \quad$ power loss to anode, $\mathrm{kW}$

T thrust, $\mathrm{N}$

Te electron temperature, $K$

$v \quad$ average exhaust velocity, $\mathrm{m} / \mathrm{s}$

$v_{\mathrm{a}} \quad$ anode voltage drop, $\mathrm{V}$

$\Delta V \quad$ velocity increment required for a mission, $\mathrm{km} / \mathrm{s}$

$n \quad$ thrust efficiency

nth $\quad\left(P-P_{L}\right) / P$, thermal efficiency

$\phi \quad$ work function of anode material, ev 


\section{CHRONOLOGY OF MPD THRUSTER TECHNOLOGY}

Research and Technology efforts using self-field and applied-field MPD arc thrusters have been conducted over the past three decades. During the 1960's and early 1970's, NASA, AVCO, MCDonnell Douglas, Giannini Scientific, ElectroOptical Systems, and others developed steady-state MPD thrusters in the 10 to $200 \mathrm{~kW}$ range. A comprehensive review of this work was reported by Nerheim and Kelly in 1967/1968 (refs. 4 to 5). Radiation cooled thrusters were designed to operate up to $40 \mathrm{~kW}$ while water-cooled devices had power capabilities in excess of $100 \mathrm{~kW}$ (refs. 6 to 9). Applied-field thrusters employed electromagnets, permanent magnets, and superconducting magnets (ref. 10). Self-field MPD arcjets were evaluated at megawatt power levels in the quasi-steady-state mode (ref. 11). In this pulsed mode, steady high-power operation has typically been achieved within a period of a few hundred microseconds. Significant efforts were also undertaken to understand the effects of vacuum facility pressure on performance measurements (ref. 12). The longest life demonstration was $500 \mathrm{hr}$ by McDonnell Douglas Corporation using a $30 \mathrm{~kW}$ ammonia device which provided $9 \times 10^{5} \mathrm{Ns}$ total impulse (ref. 7 ). Higher total impulse capability, especially at higher power levels, has been limited by cathode erosion (ref. 13). During the early 1970's, funding for high power steady-state MPD thrusters was dramatically reduced mainly because of projections of a modest space electric power capability in the 1970's and 1980's.

Research efforts continued in the USA, Europe, and Japan using primarily self-field pulsed MPD thrusters which operated in a single-shot, nonrepetitive mode (refs. 14 to 16). Pulsed or quasi-steady state MPD thrusters have been operated at multimegawatt levels for purposes of understanding the characteristics of the plasma, erosion mechanisms, stability phenomena, thruster performance, scaling relations, and electromagnetic compatibility with other systems. Space plasma experiments using a MPD arcjet, pulsed at a power of about $2 \mathrm{MW}$, were conducted aboard Space Transportation System Shuttle Orbiter-9 in 1983 (ref. 17).

Much of the recent experimental work in the USA has been conducted at Princeton University with the focus on quasi-steady state thruster modeling, scaling, erosion mechanisms, and lower power steady-state thruster experiments (refs. 18 to 20). Technology programs related to both pulsed and steady state MPD thrusters are being carried out at a variety of institutions in Japan including the Institute of Space and Astronautical Sciences, Osaka University, and the University of Tokyo (refs. 16, 21, and 22). A self-field thruster has been cyclically life-tested in Japan for one-million pulses at a 1.2 MW instantaneous power level yielding a total impulse of about $2 \times 10^{4} \mathrm{Ns}$ (ref. 23). Life limiting phenomena were observed to be electrode wear and localized insulator erosion.

Self-field, steady state thrusters have been investigated by researchers at Stuttgart University (refs. 24 and 25). Thrusters were operated with argon and nitrogen in the 100 to $300 \mathrm{~kW}$ range, producing specific impulse values up to $1200 \mathrm{~s}$ at thrust efficiencies between 15 and 20 percent. During the course of electrode erosion studies, a $200 \mathrm{~kW}$ thruster was tested for about $1 \mathrm{hr}$, producing an estimated total impulse of $3 \times 10^{4} \mathrm{Ns}$.

There is significant interest in intensifying the development of high power MPD thruster technology because of the emergence of the Pathfinder 
program which will provide the critical technology for manned excursions to the Moon and Mars (ref. 26). NASA initiated technology programs to gain insight into the performance limits and lifetime of steady-state and MPD thrusters operating in the 0.1 to $1 \mathrm{MW}$ range. These programs will ultimately have to develop high throughput vacuum facilities and performance diagnostics capable of accommodating MW-class thrusters so meaningful performance and life data can be obtained for steady-state operations.

\section{ESTIMATES OF CARGO VEHICLE PROPULSION REQUIREMENTS}

Multimegawatt cargo vehicle missions using low-thrust electric propulsion will require a mission velocity increment, $\Delta V$, in excess of $16 \mathrm{~km} / \mathrm{s}$ for LEO transfers to Mars (ref. 27). Using the data of figure 2 for the demanding Mars one-way transfer from LEO, it is estimated that thrusters would have propellant throughputs of 10000 to $30000 \mathrm{~kg}$ and a total impulse requirement for each of four thrusters as high as $1 \times 10^{9} \mathrm{Ns}$. A specific impulse of $5000 \mathrm{~s}$ was assumed. Projected thruster life requirements will be about $7500 \mathrm{hr}$ for a $10 \mathrm{MW}$ system with four thrusters operating at an efficiency of 50 percent. Trades involving higher propulsion power and improved efficiency will result in lower required thruster lifetimes.

Mission velocity increments for cargo vehicle transfer from LEO to the Moon or low lunar orbit to Mars are about $7 \mathrm{~km} / \mathrm{s}$ (refs. 28 to 30), and thus, the required thruster total impulse and operational time will be significantly less than required for LEO to Mars missions. Estimates from the data of reference 2 result in mass throughput, total impulse, and operating time per thruster for a LEO-lunar round trip of approximately $7000 \mathrm{~kg}, 4 \times 10^{8} \mathrm{Ns}$, and $4000 \mathrm{hr}$, respectively. It was assumed a total of $4 \mathrm{MW}$ would be available for four thrusters operating at a specific impulse of $5000 \mathrm{~s}$. Using separate thrusters, outbound and return legs would result in only $2000 \mathrm{hr}$ operation per thruster. It is likely that the number of thrusters will need to be minimized in order to provide system simplicity and reliability.

Continuing mission scenario development and cargo vehicle trade studies will clarify performance, lifetime, and power requirements for electric propulsion. Based on current information, it is expected that thruster power levels will be in the 0.5 to $3 \mathrm{MW}$ range for systems powers of 2 to $10 \mathrm{MW}$. Total impulse per thruster will probably be about $1 \times 10^{8}$ to $1 \times 10^{9}$ Ns for specific impulse values of 2000 to $5000 \mathrm{~s}$. Based on first order calculations of lunar and Mars cargo vehicle propulsion requirements, the MPD thruster technology goal for life should be targeted in the 2000 to $8000 \mathrm{hr}$ range per thruster.

\section{THRUSTER CONFIGURATIONS}

Early MPD thrusters, such as those shown in figure 3 , generally resembled thermal arc devices with the throat diameter made larger to permit operation in the 10 to 50 torr range (refs. 6 and 31). High power thrusters operating in the 50 to $200 \mathrm{~kW}$ range incorporated water-cooled anode and cathode assemblies. Usually, thoriated tungsten cathodes were employed. Some lower power thrusters, in the 10 to $40 \mathrm{~kW}$ range, were radiation-cooled and used tungsten electrodes. Figure 4 shows a schematic of the electrodes of a $33 \mathrm{~kW}$ radiationcooled MPD thruster that was tested for $500 \mathrm{hr}$ (ref. 7). Low power thrusters usually used solenoid magnets to produce a "magnetic nozzle" or diverging 
field configuration, which generally enhanced performance since without the applied fields, the self-fields generated were rather low. Most devices incorporated low area ratio nozzles to reduce viscous losses while some early researchers used simple coaxial electrode configurations as shown in figure 5 (ref. 32). Most of the thruster characterization was done with hydrogen, ammonia, argon, and lithium (ref. 4).

Recent high power, steady-state MPD thruster technology work has been conducted by the University of Stuttgart using a self-field thruster with a low area ratio nozzle shown in figure 6 (ref. 25 ). The water-cooled cathode and anode assemblies are separated by electrically isolated water-cooled segments. Thruster characteristics were evaluated at currents up to $4500 \mathrm{~A}$ and $270 \mathrm{~kW}$ using argon and nitrogen. Propellant flow rates were 0.2 to $1.5 \mathrm{~g} / \mathrm{s}$.

Over the last 20 years, MPD thruster operation at power levels in excess of $1 \mathrm{MW}$ has been performed using capacitor banks pulsed for periods of about $1 \mathrm{~ms}$ (refs. 1, 14, 15, and 33). These thrusters have been shown to reach quasi-steady conditions after about 10 to $50 \mu \mathrm{s}$, after which the discharge characteristics are usually stable for the remainder of the $1 \mathrm{~ms}$ pulse (ref. 18). Shown in figure 7 is a cutaway diagram of a flared anode thruster used at Princeton University (refs. 18 and 19). The thrusters have usually operated at peak power levels in excess of 2 MW in a single-shot, nonrepetitive mode. This configuration had cathode and anode diameters of 1 and $5 \mathrm{~cm}$, respectively. Argon flow rates used were in the 1 to $3 \mathrm{~g} / \mathrm{s}$ range at arc currents up to $22 \mathrm{kA}$ and voltages in the 50 to $100 \mathrm{~V}$ range.

Figure 8 shows the Osaka University quasi-steady state thruster with magnetic field coils which are connected in series with the arc current (ref. 16). The minimum anode diameter is about $2.5 \mathrm{~cm}$. Hydrogen and ammonia flow rates used were 2.7 to $4.5 \mathrm{~g} / \mathrm{s}$, respectively at arc power levels of 0.5 to $4 \mathrm{MW}$.

In many high power thrusters, propellant injection in the vicinity of the anode has been found to be effective in allowing operation at higher values of $\mathrm{J}^{2} / \dot{\mathrm{m}}$, which is a quantity found to be proportional to specific impulse (refs. 14 to 15$)$. Large values of the $3^{2} / \dot{m}$ parameter are 1 imited by the "onset phenomena" which results in an arc voltage increase, arc fluctuations and, ultimately, anode deterioration (ref. 34).

Generally, MPD thrusters operating in the 0.1 to $4 \mathrm{MW}$ range have throat or minimum anode diameters in the 1 to $10 \mathrm{~cm}$ range with cathode diameters of approximately 1 to $2 \mathrm{~cm}$. Flow rates range from 0.02 to $5 \mathrm{~g} / \mathrm{s}$. The performance of low-power MPD thrusters can be enhanced by using applied magnetic fields (ref. 10). More detailed information is needed to determine if solenoidal magnets are required for MW-class thrusters to enhance performance and/or 1 ife.

\section{PERFORMANCE MEASUREMENTS}

Evaluation of performance is critically dependent on accurate measurements of thrust for steady-state devices and impulse for quasi-steady state thrusters. The quality of these measurements can be compromised primarily by thrust stand thermal drift, vibration, acceleration of eroded electrode or insulator materials, and ambient gas entrainment into the discharge (refs. 12 , $14,19,24,25$, and 35). Clearly, the use of MW-class MPD thrusters will 
place significant demands on the design of vacuum facility pumping, thermal control systems, and performance diagnostics.

Figure 9 shows inconsistencies in the argon exhaust velocity diagnostics of a quasi-steady state, self-field thruster where impulse balance and Doppler shift methods were used (ref. 14). The specific impulse values determined by an impulse measurement increase sharply with $J^{2} / \dot{m}$ to nearly 6000 s while substantially lower values are indicated from Doppler shift diagnostics. The specific impulse calculated from the impulse measurement is extremely high for the heavy argon propellant. While there is usually a significant uncertainty in specific impulse inferred from Doppler shift measurements, it would be expected that the velocities of ionic species would be higher than those obtained by impulse measurement (ref. 31). These data point to the fact that secondary and validating measurements of thruster performance are very important.

Researchers at Stuttgart University have investigated the effects of ambient pressure on the thrust and the arc operating voltage of an argon selffield thruster operating continuously at about $70 \mathrm{~kW}$ (ref. 24). The ambient pressure was shown to have had no effect on performance in the 0.8 to $2 \times 10^{-3}$ torr range. At ambient pressures of $1 \times 10^{-2}$ torr, the arc voltage increased by about $1 \mathrm{~V}$, and the thrust decreased by a few percent, as shown in figure 10. No data were reported at pressures lower than $8 \times 10^{-4}$ torr; however, there is no indication in any of the literature that self-field MPD thruster performance is affected by ambient gases at pressures lower than $1 \times 10^{-3}$ torr (ref. 24).

The effect of vacuum facility background pressure on low-power (20 to $30 \mathrm{~kW}$ ) MPD thrusters was studied by NASA Lewis from 1965 to 1970 (refs. 31 and 36). These MPD thrusters employed solenoidal magnets, permanent magnets, or a superconducting magnet (ref. 10). The major vacuum facility effect was found to be the entrainment of background gases into the arc discharge at pressures as low as $1 \times 10^{-3}$ torr. In figure 11 , normalized thrust-to-power ratio ( $T / P$ ) is plotted versus the vacuum facility background pressure in order to examine the validity of thruster performance measurements. Thrust-to-power was chosen as the parameter of interest because there are usually changes in arc voltage as the background pressure is increased. Thrust-to-power is normalized to a baseline value of T/P at $5 \times 10^{-5}$ torr where the background pressure has not been found to influence the thrust or arc voltage. The spread in the T/P data is due to variations in propellant flow rate and the type of background facility gas employed in the tests. Figure 11 shows that deceptively high performance using hydrogen thrusters can be measured in the $1 \times 10^{-2}$ to $1 \times 10^{-1}$ torr range with nitrogen as the major ambient gas. In fact, at the high ambient pressures, the thrust could be in error by as much as a factor of two. The ammonia thrust data show a thrust degradation (compared to baseline data at $5 \times 10^{-5}$ torr) of 10 to 45 percent at $1 \times 10^{-2}$ torr depending on ammonia flow rate and type of ambient gas. At 0.1 torr, the measured thrust can be increased from the baseline value by as much as 60 percent, particularly at low ammonia flow rates $(\approx 20 \mathrm{mg} / \mathrm{s}$ ) with nitrogen and argon ambient gases. Higher ammonia flow rates, in the $60 \mathrm{mg} / \mathrm{s}$ range, generally produced thrust-to-power ratios lower than baseline values obtained at $5 \times 10^{-5}$ torr. Two competing effects were found. The background pressure could degrade thrust measurement by interferring with the basic acceleration mechanisms, and the background gas could be entrained in the discharge and accelerated to enhance thrust. Thrust 
measurement validity was found to be dependent on propellant flow rate, vacuum facil-ity pressure, and ambient gas species. These results pertain primarily to applied-field MPD thrusters where Doppler shift velocity measurements indicate acceleration of ionic species takes place as far as $10 \mathrm{~cm}$ from the anode exit plane (ref. 31). Investigators using lithium applied-field thrusters have found current streamlines follow magnetic flux lines, and up to 28 percent of the arc current was collected through a $7.6 \mathrm{~cm}$ diameter Rogowski coil located $90 \mathrm{~cm}$ from the anode exit plane (ref. 37 ). It is not surprising that the characteristics of such plasmas can be very sensitive to ambient gas pressure.

Figure 12 shows the vacuum facility pressure sensitivity to argon flow rate in the large NASA Lewis facilities (refs. 38 and 39 ). In order to maintain the low vacuum facility pressures needed to minimize ambient gas ingestion in the MPD thrusters, a diffusion pumped, sublimation pumped, or cryo-pumped environment is necessary. The maximum allowable pressure for the oil diffusion pump operation is approximately $5 \times 10^{-4}$ torr since the vapor jets collapse at higher pressures. For example, the NASA Lewis facility, using 15 diffusion pumps, will pump up to 0.1 to $0.2 \mathrm{~g} / \mathrm{s}$ of argon. At these flow rates, maximum argon thruster input power levels would be in the 0.1 to $0.2 \mathrm{MW}$ range. As indicated in figure 12, large helium panel cryo-pumps with a frontal area of about $37 \mathrm{~m}^{2}$ are projected to provide ambient pressures less than $1 \times 10^{-4}$ torr at argon flow rates in excess of $1 \mathrm{~g} / \mathrm{s}$ (ref. 39). If appropriate thruster exhaust heat exchangers are provided, the cryopump should be adequate to evaluate argon MPD thrusters operating at $1 \mathrm{MW}$. Propellants such as hydrogen or hydrogen containing molecules are poorly cryopumped by gaseous helium systems at about $26 \mathrm{~K}$. Somewhat dependent on propellant type, liquid helium and/or sublimation pumped systems may be required to adequately evaluate such MW-class thrusters.

\section{OPERATING MODES}

The electromagnetic acceleration process is a strong function of arc current, and currents in the 5 to $40 \mathrm{kA}$ range will probably be required for MW-class operation. For a given thruster geometry and mass flow rate, the current and specific impulse is limited by the "onset phenomena" where the voltage rapidly increases with current, strong arc fluctuations are observed, and ultimately anode deterioration commences (refs. 24, 34, 40, and 41). This onset of plasma instabilities is generally described by a critical value of the parameter $\left(J^{2} / \dot{m}\right)_{C}$. High currents and thus high values of $J^{2} / \dot{m}$ are required for self-field thrusters to produce the specific impulse levels of interest for energetic missions. The onset condition has been defined as that value of $\mathrm{j}^{2} / \dot{\mathrm{m}}$ when high frequency voltage fluctuations (peak to peak) exceed 10 percent of the arc voltage (ref. 24). One of the explanations for the onset condition is that at the high currents, the plasma is pinched decreasing the pressure near the anode. This condition causes a decrease in plasma density which leads to the development of a strong electric field in order to support the arc current (ref. 40). Early experiments by AVCO Corporation, using a variety of propellants, found the critical value of $\mathrm{j} 2 / \mathrm{m}$ to be approximately proportional to the inverse square root of the propellant molecular weight (ref. 14). More sophisticated formulations of this stability criteria are summarized in reference 34 .

Figure 13 shows the onset parameter obtained for many different thruster geometries, propellants and flow rates; $\left(\mathrm{J}^{2} / \dot{\mathrm{m}}\right)_{\mathrm{C}}$ varies from 10 to $350 \mathrm{kA} \mathrm{s}^{2} \mathrm{~s} / \mathrm{g}$. 
Data from references 41 to 49 as well as previous citations are shown in figure 13. Most of the onset data in the 10 to $50 \mathrm{kA}^{2} \mathrm{~s} / \mathrm{g}$ range were obtained with steady-state devices whose geometries were closely linked to electrothermal arcjets with discharge chamber (or anode) throat-to-cathode diameter ratios less than two (see figs. 4 to 6 ). The quasi-steady state thrusters, which provided onset data from 50 to $350 \mathrm{kA}^{2} \mathrm{~s} / \mathrm{g}$, had large throat-to-cathode diameter ratios of 3.4 to 5.3. In this regard, a steady state, low-power MPD arcjet had a $\left(\mathrm{J}^{2} / \dot{\mathrm{m}}\right)_{\mathrm{C}}$ value of $110 \mathrm{kA}^{2} \mathrm{~s} / \mathrm{g}$ using argon (ref. 20). This thruster had a throat-to-cathode diameter ratio of five. Onset data from the $15 \mathrm{~kW}$ steady-state thruster are very similar to that of MW-class quasi-steady state thrusters using argon propellant. The arc current capability can be further extended by using propellants lighter than argon (refs. 14 and 45) and by injecting propellant near the anode wall. By using a throat-to-cathode diameter ratio of 3.4 and anode propellant injection, an argon onset condition in excess of $300 \mathrm{kA}^{2} / \mathrm{s} / \mathrm{g}$ has been obtained (ref. 15).

The electromagnetic thrust component of a self-field MPD thruster is a function of $\mathrm{J}^{2}$ (ref. 18). The specific impulse for purely electromagnetic acceleration should then be directly related to $3^{2} / \mathrm{m}$ for self field thrusters (refs. 49 to 54). Figure 14 shows specific impulse data as a function of $\mathrm{J}^{2} / \mathrm{m}$ for various propellants over a power range from $10 \mathrm{~kW}$ to $5.6 \mathrm{MW}$. The light propellants $\left(\mathrm{H}_{2}, L i\right)$ have the highest specific impulse for a given $\mathrm{J}^{2} / \dot{\mathrm{m}}$. As shown in figure 14, some of the highest values of $\mathrm{J} / \dot{\mathrm{m}}\left(208 \mathrm{kA} \mathrm{A}^{2} \mathrm{~s} / \mathrm{g}\right)$ and specific impulse $(3000 \mathrm{~s})$ for an argon self-field thruster were obtained from a thruster with a $10 \mathrm{~cm}$ anode diameter, with anode propellant injection, and a flared anode configuration (ref. 15).

The $\mathrm{J}^{2} / \dot{\mathrm{m}}$ parameter is not a good indicator of specific impulse capability of applied-magnetic-field thrusters since acceleration mechanisms of such thrusters are more complex than those produced in self-field devices. Relatively high specific impulse measurements have been obtained from low-power thrusters using applied fields in the 0.1 to $0.2 \mathrm{~T}$ range. A specific impulse of $2800 \mathrm{~s}$ was obtained with argon at very low values of $\mathrm{j}^{2} / \mathrm{m}$ of 10 to $20 \mathrm{kA} 2 \mathrm{~s} / \mathrm{g}$ (refs. 10 and 12). The low-power, applied field thrusters have produced about the same specific impulse as MW-class thrusters which operate at values of $\mathrm{J}^{2} / \dot{\mathrm{m}}$ which are an order of magnitude higher. It has also been shown that in some MPD thruster configurations, applied magnetic fields significantly enhance performance at the MW-power level. At $\mathrm{J}^{2} / \dot{\mathrm{m}}$ of 70 to 82 , the specific impulse of a quasi-steady state hydrogen thruster was increased by 59 percent to $3500 \mathrm{~s}$ by changing from purely self-field to applied field operation (ref. 16). In this case, the peak pulsed power was 3 to $4 \mathrm{MW}$. It is clear that the applied magnetic field can be a strong optimization tool for MPD thrusters particularly at modest values of $\mathrm{j}^{2} / \mathrm{m}$. The detailed roles of applied magnetic fields in the optimization of MW-class thruster performance and lifetime limits need to be carefully examined.

\section{THRUSTER PERFORMANCE}

Increases in thruster specific impulse and efficiency can provide major benefits in reduced cargo vehicle mass in LEO and in improved payload capability. Important MPD thruster experimentally determined performance parameters are reviewed. Usually the highest values of specific impulse/efficiency for each propellant are displayed for a given reference. Data were taken from 
direct thrust measurements of steady-state and pulsed MPD thrusters. No calculated performance predictions are included in the report primarily because of the complexities involved in developing models to reliably determine electromagnetic and gas dynamic thrust contributions. For example, thrust measurements from quasi-steady state devices have been reported to be about 20 percent lower than values predicted based on current distributions in the region of the electrodes (ref. 15). Comparisons were made at relatively high arc currents where the electromagnetic thrust component was thought to heavily dominate the gas dynamic thrust contribution.

Thrust data are not cited if the average mass flow of electrode and insulator erosion products was reported to be more than 10 percent of the propellant flow rate. Since the vacuum facility pressure plays an important role in the thrust determination, only those data taken at background pressures less than $1 \times 10^{-3}$ torr are usually cited. Some thrust data taken at higher pressures are reported here if evidence was presented indicating that facility

effects were minimal.

The thrust power efficiency is defined as:

$$
n P=1 / 2 \dot{m} v^{2} \times 10^{-6}
$$

where $P$ and $\dot{m}$ are in $\mathrm{kW}$ and $\mathrm{g} / \mathrm{s}$, respectively. The thrust efficiency is:

$$
n=0.0049 \frac{\operatorname{TISP}}{\mathrm{P}}
$$

where

$$
P=P_{e}+\dot{m}_{o}
$$

Magnet power is not considered in any of the efficiency calculations. The room temperature gas power, mho, is usually small enough to be negligible. The highest contribution of $\dot{m h}_{0}$ would probably be provided by hydrogen. As an example, a typical $3.6 \mathrm{MW}$ hydrogen thruster flowrate might be $2.75 \mathrm{~g} / \mathrm{s}$ (ref. 16). In this case, mho would be only 0.3 percent of the electric power.

An upper bound on the thrust efficiency is the thermal efficiency which is a measure of the maximum amount of power that can be transferred to the propellant. The thermal efficiency for actively cooled devices is given by:

$$
\eta_{\text {th }}=\frac{P-P_{L}}{P}
$$

where $P_{L}$ is the power lost to the arcjet water cooling system. In many experiments, $P_{L}$ is simply approximated by the power lost to the anode since this loss mechanism dominates.

Figure 15 shows thermal efficiencies of water-cooled thrusters operating at power levels from 20 to $250 \mathrm{~kW}$. Data are cited from references $6,8,24$, 55 and 56. Thermal efficiencies of argon and ammonia thrusters operating at less than $130 \mathrm{~kW}$ are less than 65 percent. Hydrogen thrusters have demonstrated about 80 percent conversion of electric power to power available for 
propulsion. Most of these data are upper bounds since relatively small losses like those associated with the cathode are sometimes not included in the calculation. Thermal efficiencies were also derived from anode heat flux calculations based on temperature data from a MW-class quasi-steady state thruster (ref. 56). Thermal efficiency estimates based on anode losses vary from 78 to 87 percent in the 1 to $3 \mathrm{MW}$ range using argon as the propellant. Overall, these data imply there is potential for high performance at these high powers since the power input to the plasma increases with power level. Figure 15 also shows there is a reduction in thermal efficiency as $\mathrm{J}^{2} / \dot{\mathrm{m}}$ increases in a quasi-steady state thruster. Since increases in $\mathrm{J}^{2} / \dot{\mathrm{m}}$ are associated with increases in specific impulse, data of MW-class steady-state thrusters are needed to further examine performance sensitivities to $\mathrm{J} / \dot{\mathrm{m}}$.

The power deposited in the anode of the quasi-steady state thruster can be approximated by the sum of: (1) the power associated with the conduction electron anode voltage drop, (2) power invested in heating electrons, and (3) power associated with absorbing the electrons at the anode (ref. 56). The anode power loss $\mathrm{Pa}_{\mathrm{a}}$ is:

$$
P_{a}=J\left(V_{a}+\frac{5}{2} k T_{e}+\phi\right) \times 10^{-3}
$$

At $1.3 \mathrm{MW}$, it was estimated the power losses associated with the anode drop, heating conduction electrons, and anode work function were 14, 3, and 4 percent of the input electric power, respectively. The major anode loss was associated with depositing the kinetic energy of the conduction electrons into the anode.

Figure 16 shows the extent of typical arc electrode losses and the thrust power relative to the input electric power (refs. 24, 31, and 57). At the low input power level the specific power was $1300 \mathrm{~kJ} / \mathrm{g}$ and the specific impulse was $2500 \mathrm{~s}$. The resultant electrode losses were 57 percent. At the lower specific powers of 180 to $350 \mathrm{~kJ} / \mathrm{g}$, the electrode losses were reduced. Thrust efficiencies in these three cases were about the same and varied from 0.17 to 0.20 . The remainder of the losses are associated with dissociation, ionization, excitation, exhaust divergence, and viscous flow effects.

At present, there are no thermal efficiency or performance limit data for MW-class MPD thrusters operating in the steady-state mode. Anode losses and impacts of operating at high specific powers and high specific impulse near onset should be identified and quantified. Early in technology programs and prior to development of high-fidelity thrust-stands, thermal efficiencies for steady-state, MW-class MPD thrusters should be obtained so upper bounds on thrust efficiency can be determined.

The best MPD thruster performance data obtained to date are shown in figures 17 to 20. References are cited on each figure. Some data in the literature are not reported because of evidence of high electrode erosion. Other data are not included if the vacuum facility pressure was greater than $1 \times 10^{-3}$ torr, since this condition might influence the thrust measurements due to gas entrainment in the discharge. Hydrogen and lithium data are shown in figure 17. The best performance using hydrogen has been obtained with 
quasi-steady state devices. The thrust efficiency of about 0.43 was obtained at specific impulse values of 3500 and $4900 \mathrm{~s}$ and input power levels of 3.6 and $1.5 \mathrm{MW}$, respectively. Both self-field and applied-field devices provided high thrust efficiencies (0.43 to 0.45) (refs. 16 and 58). Higher values of thrust efficiency $(0.48$ to 0.68$)$ were obtained with 1 ithium at powers less than $20 \mathrm{~kW}$. At these low power levels, applied magnetic fields were used to provide operation at 3400 to $5400 \mathrm{~s}$ specific impulse. High performance hydrogen and lithium thrusters, operating at a specific impulse of about $5000 \mathrm{~s}$, have thrust efficiencies that are at least 20 percent $\left(\mathrm{H}_{2}\right)$ and 90 percent ( $\mathrm{Li}$ ) higher than the best efficiencies obtained with the propellants $\mathrm{NH}_{3}, \mathrm{~N}_{2} \mathrm{H}_{4}, \mathrm{Ar}$, or $\mathrm{N}_{2}$. A common property shared by hydrogen and lithium propellants is that there are virtually no losses associated with the production of multiply charged species since dissociated hydrogen can only be singly ionized, and lithium has a second ionization potential of $75 \mathrm{eV}$. Lithium may not, however, be an attractive propellant because of the potential for spacecraft contamination due to propellant condensation. Hydrogen is a very attractive propellant for lunar and Mars cargo vehicles because of its high performance, and the fact that it is likely that transportation scenarios will involve long-term storage of hydrogen/oxygen for high thrust propulsion of manned and cargo vehicles.

Figure 18 shows the performance of inert gas MPD thrusters. Specific impulse values in the 2000 to $4000 \mathrm{~s}$ range have been obtained using pulsed self-field thrusters and also low-power applied-field thrusters using argon propellant. Reported efficiencies for argon have not exceeded 0.35 . The efficiencies of high-power, argon, pulsed MPD thrusters in the 2000 to $3500 \mathrm{~s}$ specific impulse range were 0.2 to 0.3 . Significant amounts of power can be invested in the production of multiply charged argon ions, as the first three ionization potentials for argon are only 15.8, 27.6, and $40.9 \mathrm{eV}$.

Data from thrusters using nitrogen containing propellants such as $\mathrm{N}_{2}, \mathrm{NH}_{3}$, and $\mathrm{N}_{2} \mathrm{H}_{4}$, (ref. 59.) displayed in figure 19. Values of specific impulse in the 2000 to $3500 \mathrm{~s}$ range have been obtained with $30 \mathrm{~kW}$ and MW-class pulsed thrusters; the thrust efficiencies are in the 0.2 to 0.3 range. Molecular propellants containing hydrogen have been found to produce relatively high performance compared to argon because, in addition to the electromagnetic thrust component, there is also significant electrothermal acceleration (ref. 42). Ammonia and hydrazine propellants are also attractive from the system standpoint because they are space storable. On the negative side, significant amounts of power can be dissipated in the dissociation and ionization of ammonia and its products. It has been estimated that the energy cost for the ammonia molecule to fully dissociate and ionize is at least $70 \mathrm{eV}$ (ref. 31 ). Using this estimate, a fully ionized 1 MW thruster with an ammonia flow rate of $1 \mathrm{~g} / \mathrm{s}$ would have about 40 percent of its power in dissociation and ionization. A significant effort is needed to assess performance limits of these space storable propellants at megawatt power levels in both the pulsed and steady-state mode.

Figure 20 shows the thrust efficiency for various MPD thrusters operating with a wide variety of propellants over a large range of input electric power. Low power (20 to $30 \mathrm{~kW}$ ) efficiency data for hydrogen, ammonia, and argon have been reported as high as 0.30 to 0.35 . Lithium efficiencies are as high as 0.69 . In all cases, the low power devices required applied magnetic fields to attain such performance levels. Efficiency data in the 1 to $6 \mathrm{MW}$ range were obtained exclusively from quasi-steady state thrusters. The highest efficiency observed $(0.45)$ was obtained with hydrogen while data from all other propellants are grouped in the 0.10 to 0.35 range. 
If MPD thruster efficiency requirements fall in the 0.5 to 0.7 range, a significant effort will be required to determine if propellants other than hydrogen are candidates for systems required to perform energetic missions whose velocity increment, $\Delta V$, is in excess of $10 \mathrm{~km} / \mathrm{s}$. In addition to overall performance limit evaluations, it is also necessary to detail the partitioning of power in the MPD thrusters in order to clearly quantize the losses at electrodes as well as the power invested in dissociation, ionization, and excitation. Nonintrusive diagnostics methods to locally determine propellant species, charge-state, densities, and velocities will be important in the characterization of the most promising thruster configurations. Performance limit and power loss diagnostics of MW class devices will have to be performed on quasi-steady state thrusters and also steady-state thrusters which require sophisticated test environments and test stands. Final assessments must be made with steady-state thrusters since pulsed devices do not necessarily have the same cathode plasma characteristics, plasma stability relations, or degree of plasma heating for the same input specific power (ref. 25).

\section{THRUSTER LIFETIME}

First order calculations of MPD propulsion requirements for lunar and Mars cargo vehicles indicate that the total impulse and life per thruster should be $1 \times 10^{8}$ to $1 \times 10^{9} \mathrm{Ns}$ and 2000 to $8000 \mathrm{hr}$, respectively. Specific impulse was assumed to be in the 2000 to $5000 \mathrm{~s}$ range with power per thruster of 0.5 to $3 \mathrm{MW}$. With these thruster endurance targets in mind, the present state-of-theart will be briefly characterized. Table I shows the best total impulses and extended test demonstrations of MPD thrusters. A quasi-steady state device was operated $1 \times 10^{6}$ cycles with ammonia at $1.2 \mathrm{MW}$ to produce $2 \times 10^{4} \mathrm{Ns}$ or a total operating time of about $0.2 \mathrm{hr}$ (ref. 23). Steady-state thrusters in the 0.1 to $0.3 \mathrm{MW}$ range have been operated for periods of 1 to $50 \mathrm{hr}$ to produce about $5 \times 10^{4} \mathrm{Ns}$ total impulse (refs. 24 and 25). In 1969. McDonnell Douglas conducted a 500-hr test with a low power ( $33 \mathrm{~kW}$ ) MPD thruster which provided about $1 \times 10^{6}$ Ns (ref. 7).

Technology demonstrations of MPD thrusters to date have produced total impulse values that are two to three orders of magnitude below estimated requirements for cargo vehicle propulsion. Since extended testing of an MPO thruster is very expensive, short-term tests are usually conducted to determine the mass loss of the cathode. The cathode is the most likely component to fail if operation is not conducted above the "onset" condition. Cathode mass loss has been directly measured or in situ measurements have been made using radioactive tracers (ref. 19). Cathode erosion rate data are also shown in Table I. A quasi-steady state thruster (ref. 23) demonstrated a million cold starts. Because of the cold starts, a higher erosion rate of 3600 $\mathrm{g} / \mathrm{kA} / \mathrm{khr}$ was obtained. Reported cathode erosion rates for steady-state thrusters vary from $100 \mathrm{~g} / \mathrm{kA} / \mathrm{khr}$ in the stuttgart thruster to $0.14 \mathrm{~g} / \mathrm{kA} / \mathrm{khr}$ which is the remarkable value obtained by Giannini Scientific (GS) in 1964 (ref. 8). The GS thruster was tested for $50 \mathrm{hr}$ at about $2.1 \mathrm{kA}$. The very low rate was attributed to operation at very low chamber pressures which allowed the arc to spread over a large surface of the cathode (ref. 60). Application of a lowpower electromagnet may also have been a factor in the successful experiment. It was reported that an applied field of about $0.15 \mathrm{~T}$ improved anode life by preventing arc attachment on the anode in the form of localized spots. The effects of applied-magnetic fields on the life of both electrodes was found to be dependent on thruster geometry, arc current and the type of propellant in the limited number of tests conducted by Giannini Scientific (ref. 61). 
To provide some understanding of the cathode erosion rate impact on lifetime, cathode erosion data are shown in Table II, and end-of-life estimates are made. It was assumed that the erosion rate is linear with respect to current and operating time. It was further assumed that a 10 percent cathode mass loss (in the discharge region) represents an end-of-life condition; this criteria is consistent with the lamp industry and resistojet heater end-oflife predictions (ref. 62). Assumptions concerning cathode diameter and discharge conditions ( $J=5000 \mathrm{~A}$ ) are shown in Table II. The projected lifetimes of the quasi-steady state, $0.27 \mathrm{MW}$ self-field, low-power applied field, and $0.12 \mathrm{MW}$ applied field thrusters using these assumptions are $0.6,21,240$, and $15000 \mathrm{hr}$. From these estimates, the projected life of steady-state MPD thrusters may possibly be improved by a factor of 700 by appropriate selection of design and operating conditions.

Figure 21 shows the cathode erosion rate versus arc current including a larger data base. Data from references 63 to 65 as well as previous citations are shown in figure 21. The highest erosion rates are associated with coldstart pulsed devices which used thoriated tungsten rod cathodes. Generally, about an order of magnitude lower rates were obtained with pulsed thrusters using porous tungsten cathodes impregnated with barium compounds. Heavy erosion generally takes place on a cathode cold start and results in ejection of glowing particles (ref. 24). Since pulsed devices are usually started cold, the cathode erosion rates are extremely high and range from $1 \times 10^{3}$ to $1 \times 10^{5} \mathrm{~g} / \mathrm{kA} / \mathrm{khr}(3$ to $30 \mathrm{\mu g} / \mathrm{C})$. Cathodes with such erosion rates cannot be expected to operate reliably for more than a few hours.

In the steady-state, hot-cathode operation, cathode erosion takes place at a much lower rate (ref. 24). Most of the steady-state cathode erosion rate data fall in the range of 9 to $250 \mathrm{~g} / \mathrm{kA} / \mathrm{khr}(0.003$ to $0.07 \mu \mathrm{g} / \mathrm{C})$ as shown in figure 21. Such erosion rates would result in very high cathode mass losses which are inconsistent with MPD thruster lifetimes of a few thousand hours at arc currents in excess of $10 \mathrm{kA}$.

The lowest cathode erosion rate was $0.14 \mathrm{~g} / \mathrm{kA} / \mathrm{khr}$. The steady-state MPD thruster used to obtain this data was operated with hydrogen at an arc current of $2.1 \mathrm{kA}$ (ref. 8). An MPD thruster with such a cathode erosion rate would very likely be capable of operating at megawatt power levels for thousands of hours. The Giannini Scientific experiment (ref. 8) should be re-evaluated in order to better understand electrode wear mechanisms and determine potential impacts on performance.

The MPD thruster extended tests indicate the total impulse demonstrated with state-of-the-art MPD thrusters needs to be increased by at least two to three orders of magnitude to satisfy cargo vehicle propulsion estimated requirements. Cathode erosion rates for most current thrusters are in excess of $\mathrm{g} \mathrm{g} / \mathrm{kA} / \mathrm{khr}(0.003 \mu \mathrm{g} / \mathrm{C})$ which is unacceptable for 5 to $10 \mathrm{kA}$ operation for a few thousand hours. Tests conducted over two decades ago offer encouragement that cathode erosion rates may be further reduced by nearly two orders of magnitude to values near $0.1 \mathrm{~g} / \mathrm{kA} / \mathrm{khr}$ (ref. 8).

\section{CONCLUDING REMARKS}

Space transportation scenarios and development of requirements for exploration class missions are ongoing. Thruster power for low-thrust cargo vehicle 
propulsion is estimated to be in the 0.5 to $3 \mathrm{MW}$ range, with total impulses of $1 \times 10^{8}$ to $1 \times 10^{9} \mathrm{Ns}$ at specific impulse levels of 2000 to $5000 \mathrm{~s}$. MPD thruster lifetimes of 2000 to 8000 hours will probably be required.

MPD thruster technology has been pursued for about 25 years, although major industrial programs in the USA for the development of high power thruster technology ceased circa 1970. Plasma research related to MPD thrusters continued from 1970 to present primarily at universities in the USA, Japan, and Europe. Most of the research centered on the quasi-steady state devices which minimize test facilities requirements.

Over the last three decades, a significant effort has been expended to determine the effect of vacuum facility background pressure on performance. There is no evidence in the literature that self-field thrusters are affected by background gases at pressures less than $1 \times 10^{-3}$ torr. With the appliedfield thruster, two competing effects involving background pressure were found. The background pressure could degrade thrust by interfering with the acceleration mechanisms, and the background gas could be entrained in the discharge to enhance thrust. In order to minimize vacuum facility effects on applied field thruster performance, diagnostic measurements should be carried out in a vacuum environment whose pressure is less than $3 \times 10^{-4}$ torr. Existing vacuum facilities are adequate to handle the flow of argon or nitrogen MPD thrusters operating in excess of $1 \mathrm{MW}$ input power. Development work will be required for MW-class test stands. Testing of MW-class thrusters using hydrogen containing propellants will require modifications to vacuum facilities and thermal control systems. In addition to high throughput vacuum systems, high fidelity test stands are required to adequately characterize MPD thruster performance. A detail definition of the appropriate test environment for a MW-class MPD thruster has not been defined.

Since high specific impulse is related to high current capability at relatively low flow rates, definition of operating modes and stability limits become important. Flared anode MPD thrusters operating in the quasi-steady state mode have demonstrated arc currents up to $31 \mathrm{kA}$ (at $3 \mathrm{~g} / \mathrm{s}$ ) by injecting argon propellant near the anode wall. Onset parameters $\left(\mathrm{J}^{2} / \mathrm{m}\right)$ were in the 300 to $350 \mathrm{kA}^{2} \mathrm{~s} / \mathrm{g}$ range. Argon specific impulse values as high as $3000 \mathrm{~s}$ have been reported at a j2/m of $200 \mathrm{kA}^{2} \mathrm{~s} / \mathrm{g}$. Significant increases in onset parameter, current capability, and specific impulse have been demonstrated by using propellants lighter than argon.

Thermal efficiencies which provide an upper-bound on thrust efficiencies have been reported to be about 0.60 for steady-state-argon and ammonia thrusters at powers of approximately $0.1 \mathrm{MW}$. Hydrogen thrusters $(0.2 \mathrm{MW})$ had thermal efficiencies as high as 0.80 while argon pulsed devices had thermal losses estimated at only 13 percent at $3 \mathrm{MW}$. These data imply there is potential for high performance at the high power levels.

Relatively high MPD thruster efficiencies of 0.43 and 0.69 were obtained at about $5000 \mathrm{~s}$ specific impulse using hydrogen and lithium, respectively. The hydrogen thruster was a quasi-steady state device, while the lithium data were obtained with a $20 \mathrm{~kW}$ steady-state-thruster. Steady-state and pulsed argon thrusters have demonstrated efficiencies of 0.30 to 0.34 at 2400 to $2800 \mathrm{~s}$ specific impulse. All other propellants $\left(\mathrm{NH}_{3}, \mathrm{~N}_{2} \mathrm{H}_{4}, \mathrm{~N}_{2}\right.$, He, and $\left.\mathrm{Ne}\right)$ produced efficiencies of 0.10 to 0.30 in the 1000 to $4500 \mathrm{~s}$ specific impulse range. Propellants that are attractive from the systems storage standpoint 
$\left(\mathrm{NH}_{3}, \mathrm{~N}_{2} \mathrm{H}_{4}\right.$, and $\mathrm{Ar}$ ) suffer anode losses that are probably 15 to 40 percent of the input power as well as large losses associated with dissociation, excitation, and multiple ionization of propellant species. Very generaliy, the efficiency and specific impulse limits have been increased by using a throat-to-cathode diameter of at least 3.4, anode propellant injection, a flared-anode geometry, and light propellants. In some thruster geometries applied magnetic fields play an important role. By changing from purely selffield to applied magnetic field, the specific impulse of a pulsed hydrogen thruster was increased by nearly 60 percent. The maximum thrust efficiencies of applied-field devices operating at less than $50 \mathrm{~kW}$ with ammonia or argon are about the same as the best data from pulsed MW-class thrusters using these propellants. Effects of applied magnetic fields in the optimization of MW-class thrusters should be further examined. There is also a need for performance limit evaluations and determination of losses associated with electrodes, dissociation, ionization, and excitation. Nonintrusive diagnostic methods need to be developed to determine propellant species, charge state, densities and velocities so accurate theoretical treatments of the MPD plasma acceleration and energy transfer processes can be further developed.

Extended tests of pulsed and steady-state MPD thrusters have demonstrated total impulse capabilities of about $2 \times 10^{4} \mathrm{Ns}$ and $1 \times 10^{6} \mathrm{Ns}$, respectively. The longest operating time was $500 \mathrm{hr}$ for a $33 \mathrm{~kW}$ ammonia MPD thruster with $1900 \mathrm{~s}$ specific impulse. The demonstrated total impulse values are at least two to three orders of magnitude below that required for cargo vehicle propulsion.

Cathode erosion rates have been used as a thruster lifetime figure-ofmerit since the cathode is considered the most likely component to fail if operation is not conducted above the "onset" condition. Enormous cathode erosion rates in the $10^{3}$ to $10^{5} \mathrm{~g} / \mathrm{kA} / \mathrm{khr}$ range have been observed for pulsed situations with many cold-starts. Steady state evaluations yield rates over a wide range, 0.14 to $250 \mathrm{~g} / \mathrm{kA} / \mathrm{khr}$. Acceptably low rates $(0.14 \mathrm{~g} / \mathrm{kA} / \mathrm{khr})$ were obtained with a low pressure arc chamber and a low current applied electromagnetic field which apparently uniformly distributed the arc current over a large cathode area. An experimental and analytical effort is needed to thoroughly examine the effects of electrode design, applied fields, and operating conditions on electrode lifetime.

\section{REFERENCES}

1. Butler, J., and Brothers, B., "Mission and Space Vehicle Sizing Data for a Chemical Propulsion/Aerobraking Option," Manned Mars Missions, Working Group Papers, NASA TM-89320, Vol. 1, Sect. 1-4, M.B. Duke and P.W. Keaton, eds., 1986, pp. 263-274.

2. Palaszewski, B., Personal Communication, Jet Propulsion Laboratory, Pasadena, CA, Nov. 1987.

3. Keaton, P.W., "Low-Thrust Rocket Trajectories," Los Alamos National Laboratory Report, LA-10625-MS, Jan. 1986.

4. Nerheim, N.M., and Kelly, A.J., "A Critical Review of the State-of-theArt of the MPD Thruster," AIAA Paper 67-688, Sept. 1967. 
5. Nerheim, N.M., and Kelly, A.J., "A Critical Review of the Magnetoplasmadynamic (MPD) Thruster for Space Applications," JPL-TR-32-1196, Jet Propulsion Laboratory, California Institute of Technology, Pasadena, CA, Feb. 1968, NASA CR-93139.

6. "Arcjet Technology Research and Development," RAD-TR-65-37, AVCO Corp., Wilmington, MA, Dec. 1965, NASA CR-54687.

7. Esker, D.W., Checkley, R.J., and Kroutil, J.C., "Radiation Cooled MPD ArC Thruster," MDC-H296, McDonnell-Douglas Corp., St. Louis, MO, July 1969, NASA CR-72557.

8. Ducati, A.C., Muehlberger, E., and Todd, J.P., "Design and Development of a Thermo-Ionic Electric Thrustor," NASA-CR-59804, 1964.

9. Ducati, A.C., Muehiberger, E., and Giannini, G., "High Specific Impulse Thermo-Ionic Acceleration," AIAA Paper 64-668, Sept. 1964.

10. Connolly, D.J., Bishop, A.R., and Seikel, G.R., "Tests of Permanent Magnet and Superconducting MPD Thrusters," AIAA Paper 71-696, July 1971. (NASA TM X-67827).

11. Clark, K.E., and Jahn, R.G., "Quasi-Steady Plasma Acceleration," AIAA Journal, Vol. 8, No. 2, Feb. 1970, pp. 216-220.

12. Connolly, D.J., Sovie, R.J., Michels, C.J., and Burkhart, J.A., "Low Environmental Pressure MPD Arc Tests," AIAA Journal, Vol. 6, No. 7, July 1968, pp. 1271-1276.

13. Polk, J.E., von Jaskowsky, W., Kelly, A.J., and Jahn, R.G., "Measurement of MPD Thruster Erosion Using Surface Layer Activation," Journal of Propulsion and Power, Vol. 3., No. 1, Jan.-Feb. 1987, pp. 33-38.

14. Malliaris, A.C., John, R.R., Garrison, R.L., and Libby, D.R., "Quasi-Steady MPD Propulsion at High Power," AVSD-0146-71-RR, AVCO Corp., Wilmington, MA, Feb. 1971, NASA-CR-111872.

15. Wolff, M., Kelly, A.J., and Jahn, R.G., "A High Performance Magnetoplasmadynamic Thruster," 17 th International Electric Propulsion Conference, Japan Society for Aeronautical and Space Sciences, Tokyo, Japan, 1984, pp. 206-212.

16. Tahara, H., Yasui, H., Kagaya, Y., and Yoshikawa, T., "Development of a Quasi-Steady MPD Arcjet Thruster for Near-Earth Missions, " AIAA Paper 87-1001, May 1987.

17. Kuriki, K., Morimoto, S. and Nakamaru, K., "Flight Performance Test of a MPO Thruster System," AIAA Paper 81-0664, Apr. 1981.

18. Gilland, J.H., Kelly, A.J., and Jahn, R.G., "MPD Thruster Scaling," AIAA Paper 87-0997, May 1987.

19. Polk, J.E., Kelly, A.J., and Jahn, R.G., "MPD Thruster Erosion Research," AIAA Paper 87-0999, May 1987. 
20. Myers, R., Kelly A.J., and Jahn, R.G., "Electrothermal-Electromagnetic Hybrid Thruster Research," AIAA Paper 87-1018, May 1987.

21. Arakawa, Y., and Sasoh, A., "Steady-State Permanent Magnet MPD Thruster," AIAA Paper 87-1021, May 1987.

22. Kuriki, K., Shimizu, Y., and Nishida, E., "Anode Configuration for Electrothermal/Electromagnetic Arcjet," AIAA Paper 87-1024, May 1987.

23. Shimizu, Y., Kuriki, K., Morimoto, S., Suzuki, H., Uematsu, K., Enya, S., and Takiyama, T., "Endurance Test of MPD Arcjet Discharge Chamber," 17th International Electric Propulsion Conference, Japan Society for Aeronautical and Space Sciences, Tokyo, Japan, 1984, pp. 186-192.

24. Kurtz, H.L., Auweter-Kurtz, M., and Schrade, H.O., "Self-Field MPD Thruster Design-Experimental and Theoretical Investigations," AIAA Paper 85-2002, Sept. 1985.

25. Kurtz, H.L., Auweter-Kurtz, M., Merke, W., and Schrade, H.O., "MPD Thruster Investigations," AIAA Paper 87-1019, May 1987.

26. Ride, S.K., "Leadership and America's Future in Space," NASA TM-89638, 1987.

27. Babb, G.R., and Stump, W.R., "Comparison of Mission Design Options for Manned Mars Missions," Manned Mars Missions, Working Group Papers, NASA TM-89320, Vol. 1, Sect. 1-4, M.B. Duke and P.W. Keaton, eds., 1986, pp. 37-52.

28. King, J.C., "A Natural First Approximation to Low-Thrust Trajectories Between Satellite Orbits of the Earth and Moon," AIAA Journal, Vol. 3, No. 8, Aug. 1965, pp. 1432-1439.

29. Keaton, P.W., and Tubb, D.J., "Nuclear Electric Propulsions," Manned Mars Missions, Working Group Papers, NASA TM-89320, Vol. 1, Sect. 1-4, M.B. Duke and P.W. Keaton, eds., 1986, pp. 129-141.

30. Galecki, D.L., and Patterson, M.J., "Nuclear Powered Mars Cargo Transport Mission Utilizing Advanced Ion Propulsion," AIAA Paper 87-1903, June 1987. (NASA TM-100109).

31. Connolly, D.J., Sovie, R.J., and Seikel, G.R., "Performance and Diagnostics of a Water-Cooled Magnetoplasmadynamic Arc Thruster," NASA TN D-5836, 1970 .

32. Patrick, R.M., and Schneiderman, A.M., "Performance Characteristics of a Magnetic Annular Arc," AIAA Journal, Vol. 4, No. 2, Feb. 1966, pp. 283-290.

33. Clark, K. E., DiCapua, M.S., Jahn, R.G., and von Jaskowsky, W.F., "Quasi-Steady Magnetoplasmadynamic Arc Characteristics," AIAA Paper 70-1095, Aug. 1970.

34. Lawless, J.L., and Subramaniam, V.V., "Theory of Onset in Magnetoplasmadynamic Thrusters," Journal of Propulsion and Power, Vol. 3 , No. 2, Mar.-Apr. 1987, pp. 121-127. 
35. Toki, K., "Quasisteady MPD Arcjet with Hollow Cathode," Journal of Propulsion and Power, Vol. 2, No. 5, Sept.-Oct. 1986, pp. 402-407.

36. Sovie, R.J., and Connolly, D.J., "Effect of Background Pressure on Magnetoplasmadynamic Thruster Operation," Journal of Spacecraft and Rockets, Vol. 7, No. 3, Mar. 1970, pp. 255-258.

37. Fradkin, D.B., Blackstock, A.W., Roehling, D.J., Stratton, T.F., Williams, M., and Liewer, K.W., "Experiments Using a 25-kW Hollow Cathode Lithium Vapor MPD Arcjet," AIAA Journal, Vol. 8, No. 5, May 1970, pp. 886-894.

38. Finke, R.C., Holmes, A.D., and Keller, T.A., "Space Environment Facility for Electric Propulsion Systems Research," NASA TN D-2774, 1965.

39. Vetrone, R., Personal Communication, NASA Lewis Research Center, Cleveland, $\mathrm{OH}$, June 1988.

40. Barnett, J.W., and Jahn, R.G., "Onset Phenomena in MPD Thrusters," AIAA Paper 85-2038, Oct. 1985.

41. Schrade, H.O., Auweter-Kurtz, M., and Kurtz, H.L., "Stability Problems in Magnetoplasmadynamic Arc Thrusters," AIAA Paper 85-1633, July 1984.

42. Yoshikawa, T., Kagaya, Y., and Tahara, H., "Thrust Measurement of a Quasi-Steady MPD Arcjet," AIAA Paper 85-2003, Sept. 1985.

43. Hugel, H., "Flow Rate Limitations in the Self-Field Accelerator, "AIAA Paper 73-1094, Oct. 1973.

44. Burton, R.L., Clark, K.E., and Jahn, R.G., "Thrust and Efficiency of a Self-Field MPD Thruster," AIAA Paper 81-0684, Apr. 1981.

45. Yoshikawa, T., Kagaya, Y., and Kuriki, K., "Thrust and Efficiency of the K-III MPD Thruster," Journal of Spacecraft and Rockets, Vol. 21, No. 5, Sept.-Oct. 1984, pp. 481-487.

46. Merfeld, D.J., Kelly, A.J., and Jahn, R.G., "MPD Thruster Performance: Propellant Distribution and Species Effects, "Journal of Propulsion and Power, Vol. 2, No. 4, July-Aug. 1986, pp. 317-322.

47. Rudolph, L.K., Jahn, R.G., Clark, K. E., and von Jaskowsky, W.F., "Performance Characteristics of Quasi-Steady MPD Discharges," AIAA Paper 76-1000, Nov. 1976.

48. Sovie, R.J., and Connolly, D.J., "A Study of the Axial Velocities in an Ammonia MPD Thruster," AIAA Journal, Vol. 7, No. 4, Apr. 1969, pp. 723-725.

49. Figiwara, T., Aoki, M., and Ao, T., "Experimental Study of MPD Thruster Performance," 15th International Symposium on Space Technology and Science," Vol. 1, H. Matsuo, ed., AGNE Publishing, Tokyo, Japan, 1986, pp. 109-119.

50. Kagaya, Y., Yoshikawa, T., and Tahara, H., "Quasi-Steady MPD Arcjets with Applied Magnetic Fields," AIAA Paper 85-2001, Oct. 1985. 
51. Toki, K., Kuriki, K., and Sumida, M., "Multi-Channel Two Dimensional MPD Arcjet," AIAA Paper 87-1000, May 1987.

52. Connolly, D.J., and Sovie, R.J., "Performance of Radiation-Cooled Magnetoplasmadynamic Arc Thrusters," NASA TM X-1908, 1969.

53. Kagaya, Y., Yokoi, Y., Tahara, H., and Yoshikawa, T., "Thrust Performance and Current Distribution in a Quasi-Steady MPD Arcjet," 17th International Electric Propulsion Conference, Japan Society for Aeronautical and Space Sciences, Tokyo, Japan, 84-31, 1984, pp. 200-205.

54. Kuriki, K. Uematsu, K., and Morimoto, S., "MPD Arcjet Performance With Various Propellants," AIAA Paper 82-1885, Nov. 1982.

55. Bennett, S., Enos, G., John, R., and Powers, W., "Magnetoplasmadynamic Thrustor Research," AVSSD-0272-67-RR, Avco Corp., Lowe 11, MA, May 1967, NASA CR-72345.

56. Saber, A.J., and Jahn, R.G., "Anode Power Deposition in Quasi-Steady MPD Arcs," AIAA Paper 73-1091, Oct. 1973.

57. Sakiyama, M., Iwata, A., Yoshiwa, M., Yoshida, R., Kagaya, Y., Wasa, T., Tahara, H., and Yoshikawa, T., "Continuous Operation Test of Quasi-Steady MPD Thruster with a Ring Coil," AIAA Paper 87-1045, May 1987.

58. Uematsu, K., Mori, K., Kuninaka, H., and Kuriki, K., "Effect of Electrode Configuration on MPD Arcjet Performance," 17 th International Electric Propulsion Conference, Japan Society for Aeronautical and Space Sciences, Tokyo, Japan, 1984, pp. 79-86.

59. Uematsu, K., Ishii, M., and Kuriki, K., "Development of 1 KW MPD Thruster," AIAA Paper 87-1023, May 1987.

60. Ducati, A.D., Muehlberger, E., and Giannini, G., "High Specific Impulse Thermo-Ionic Acceleration," AIAA Paper 64-668, Aug. 1964.

61. Ducati, A.C., Jahn, R.G., Muehlberger, E., and Treat, R.P., "Design and Development of a Thermo-Ionic Electric Thruster," FR-056-968, Giannini Scientific Corp., Santa Ana, CA, May 1966, NASA CR-54703.

62. Morren, W.E., Whalen, M.V., and Sovey, J.S., "Performance and Endurance Tests of a Multipropellant Resistojet for Space Station Auxiliary Propulsion," AIAA Paper 86-1435, June 1986. (NASA TM-87278).

63. Jones, R.E., and Walker, E.L., "Status of Large Vacuum Facility Tests of an MPD Arc Thruster," NASA TM X-52155, 1965.

64. Yoshikawa, T., Kagaya, Y., Yokoi, Y., and Tahara, H., "Performance Characteristics of Quasi-Steady MPD Thrusters," 17th International Electric Propulsion Conference, Japan Society for Aeronautical and Space Sciences, Tokyo, Japan, 1984, pp. 396-403.

65. Schrade, H.O., Auweter-Kurtz, M., and Kurtz, H.L., "Cathode Erosion Studies on MPD Thrusters," AIAA Journal, Vol. 25, No. 8, Aug. 1987, pp. 1105-1112. 
TABLE I. - DEMONSTRATED LIFE

[Uncertainty in performance may exist due to the facility effects. SS: Steady state.]

\begin{tabular}{|l|r|r|r|r|}
\hline & \multicolumn{2}{|c|}{ Self-field } & \multicolumn{1}{c|}{ Applied field } \\
\cline { 2 - 5 } & Quasi-steady state & \multicolumn{1}{c|}{ SS } & \multicolumn{1}{c|}{ SS } & \multicolumn{1}{c|}{ SS } \\
\hline $\begin{array}{l}\text { Demonstrated total } \\
\text { impulse, Ns }\end{array}$ & $2 \times 10^{4}$ & $3 \times 10^{4}$ & $1 \times 10^{6}$ & $5 \times 10^{4}$ \\
Operating time, hr & 0.2 & 1 & 500 & 50 \\
Cathode erosion rate, \\
g/kA/khr
\end{tabular}

TABLE II. - CATHODE LIFE ESTIMATE

\begin{tabular}{|c|c|c|c|c|}
\hline \multicolumn{5}{|c|}{ Assumption } \\
\hline \multicolumn{5}{|c|}{$\begin{array}{l}\text { Steady state operation } \\
1 \mathrm{~cm} \text { diam. by } 8 \mathrm{~cm} \text { long thoriated tungsten cathode } \\
0.5 \mathrm{MW} \text { thruster, } 5000 \mathrm{~A}, 100 \mathrm{~V} \\
\text { Constant erosion rate } \\
10 \text { percent cathode mass loss is end of } 1 \text { ife }\end{array}$} \\
\hline \multicolumn{5}{|c|}{ Result } \\
\hline Reference & 23 & 24,25 & 7 & 8,60 \\
\hline $\begin{array}{l}\text { Catode Erosion } \\
\text { rate, } \mathrm{g} / \mathrm{kA} / \mathrm{khr} \\
\text { End-of-life, hr } \\
\text { (estimate) }\end{array}$ & $\begin{array}{r}3600 \\
0.6\end{array}$ & $\begin{array}{r}100 \\
21\end{array}$ & $\begin{array}{r}9 \\
240\end{array}$ & $\begin{array}{r}0.14 \\
15 \quad 000\end{array}$ \\
\hline
\end{tabular}




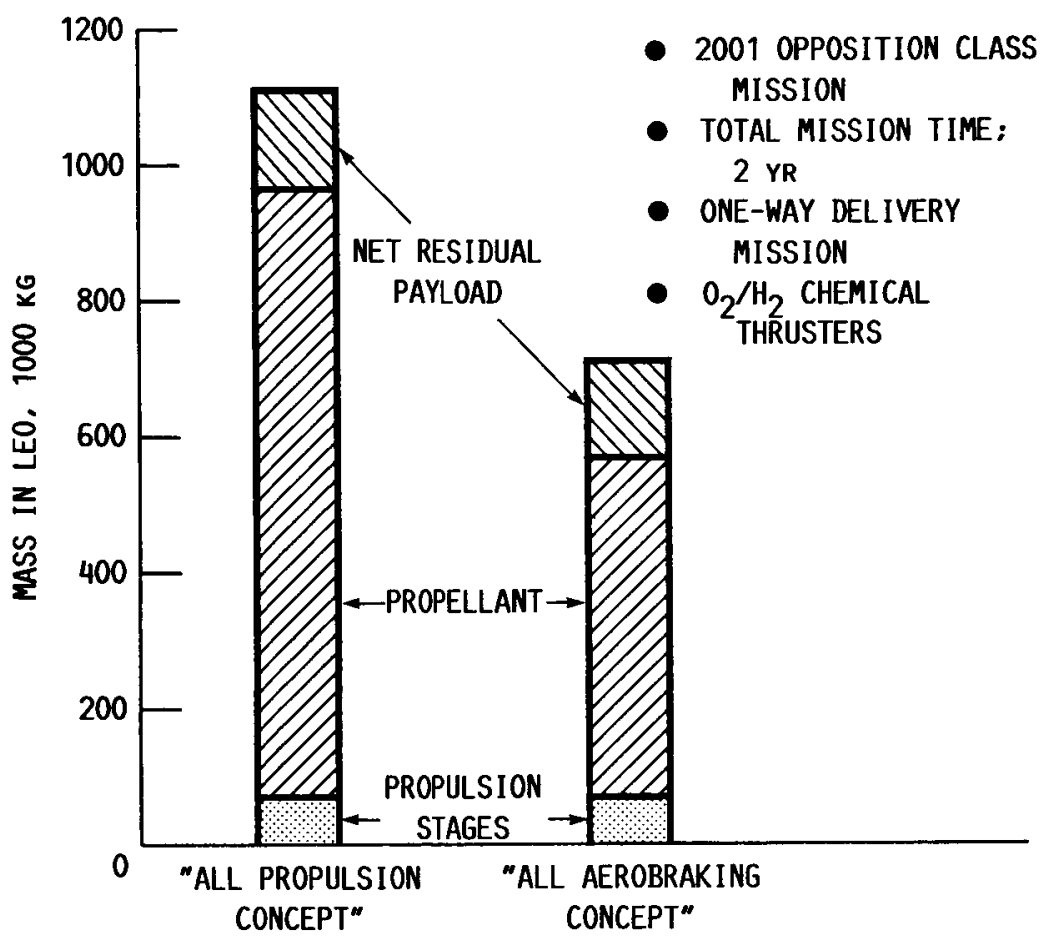

FIGURE 1. - MARS CARGO VEHICLE MASS IN LEO USING CHEMICAL PROPULSION.

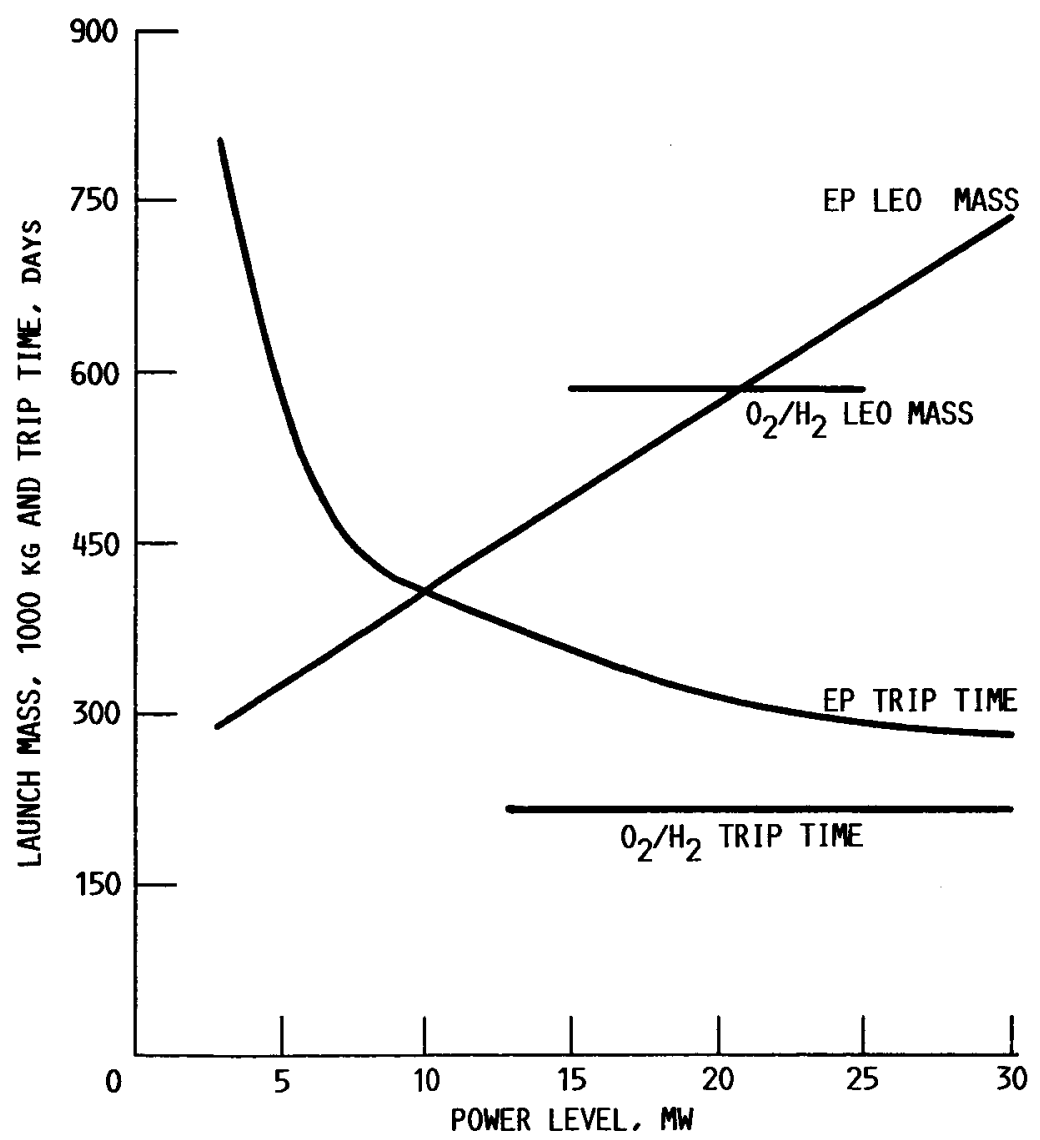

FIGURE 2. - MARS CARGO VEHICLE TRIP TIME AND LAUNCH MASS. PAYLOAD MASS: $180000 \mathrm{kG}$, ELECTRIC PROPULSION SPECIFIC MASS: $10 \mathrm{kG} / \mathrm{kW}$, SPECIFIC IMPULSE: $5000 \mathrm{~s}, \mathrm{O}_{2} / \mathrm{H}_{2}$ SPECIFIC IMPULSE: $480 \mathrm{~s}$. 


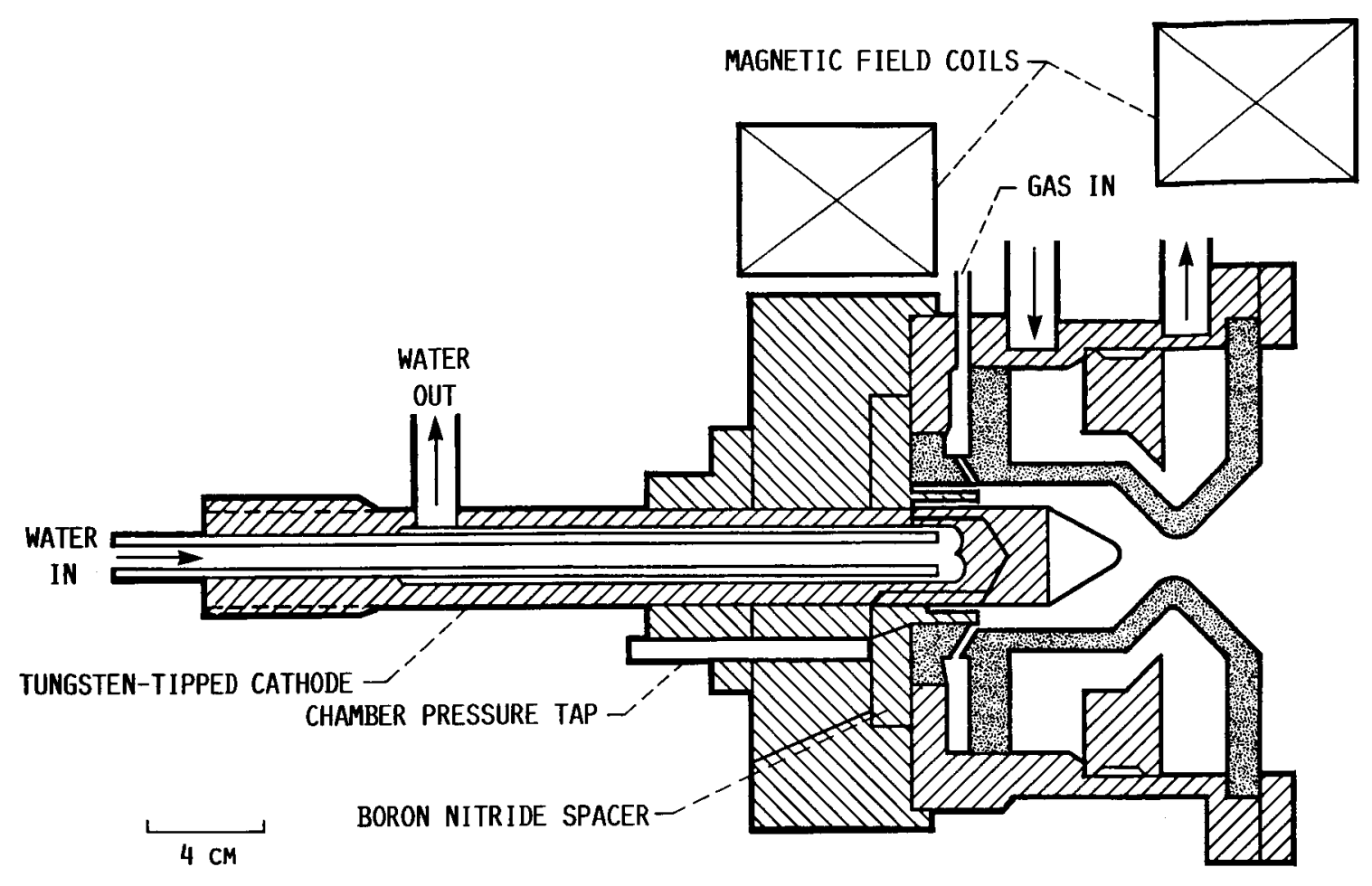

FIGURE 3. - APPLIED-FIELD MPD THRUSTER.

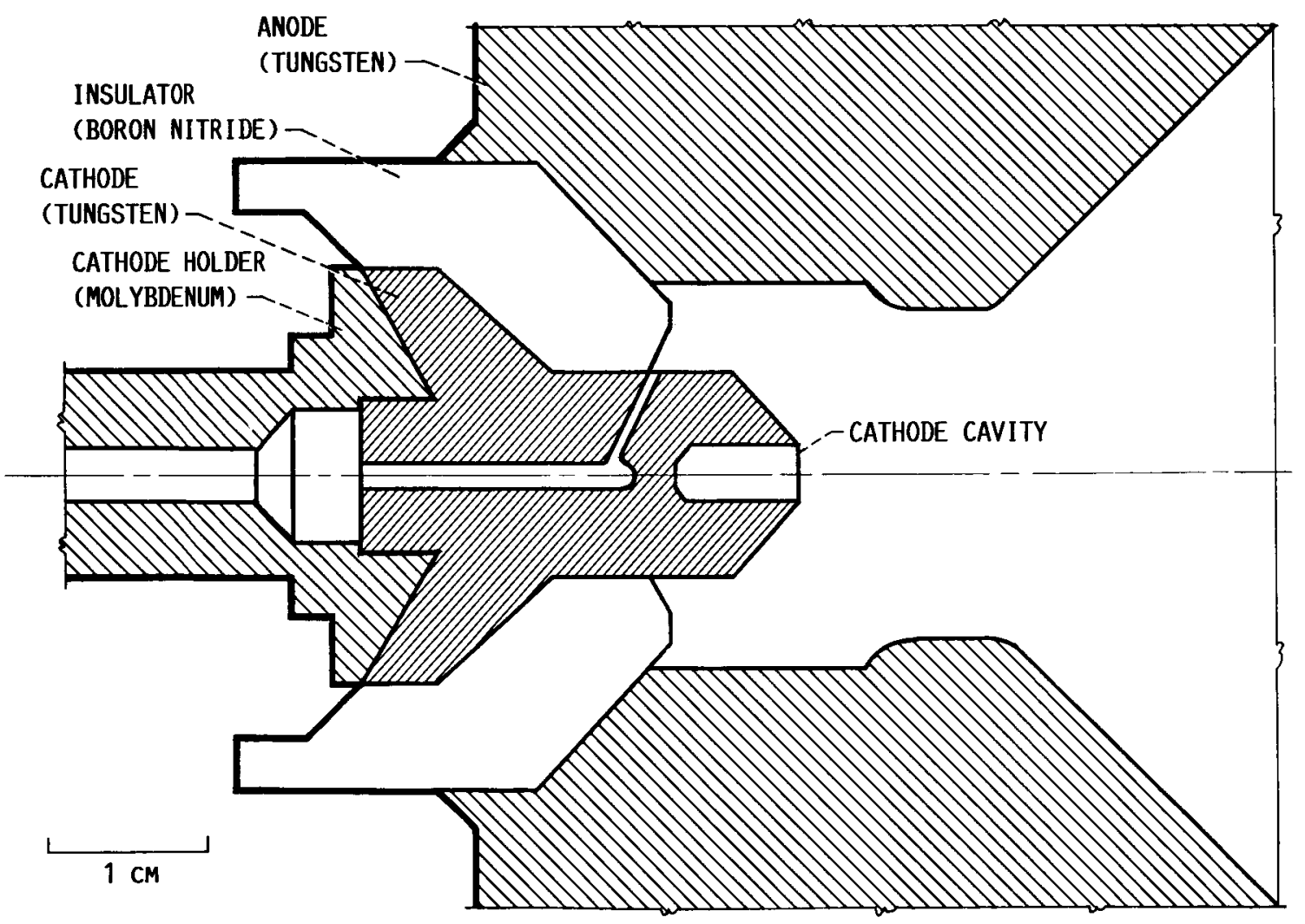

FIGURE 4. - RADIATION-COOLED THRUSTER ELECTRODE ASSEMBLY. 


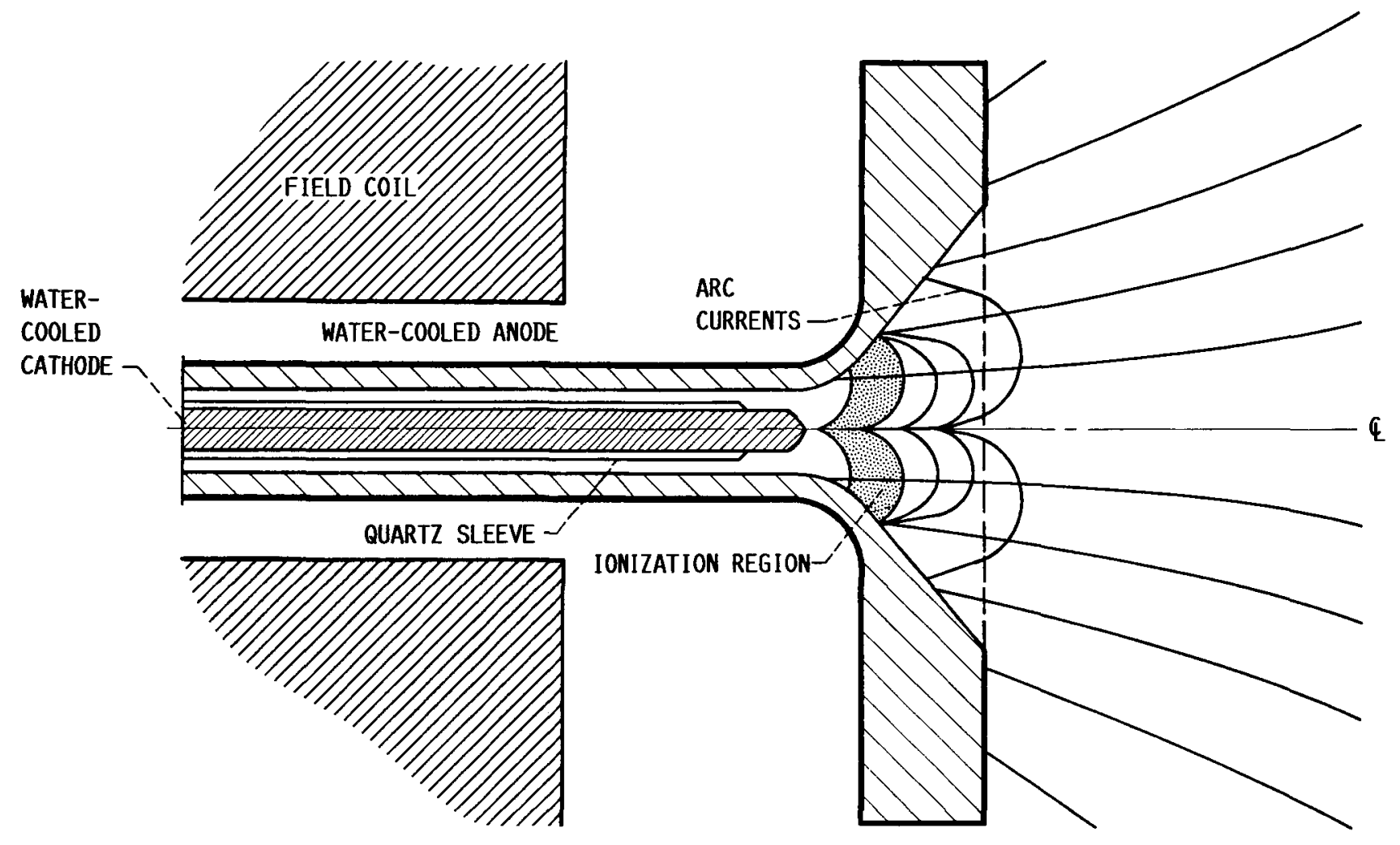

FIGURE 5. - MAGNETIC ANNULAR ARCJET. 


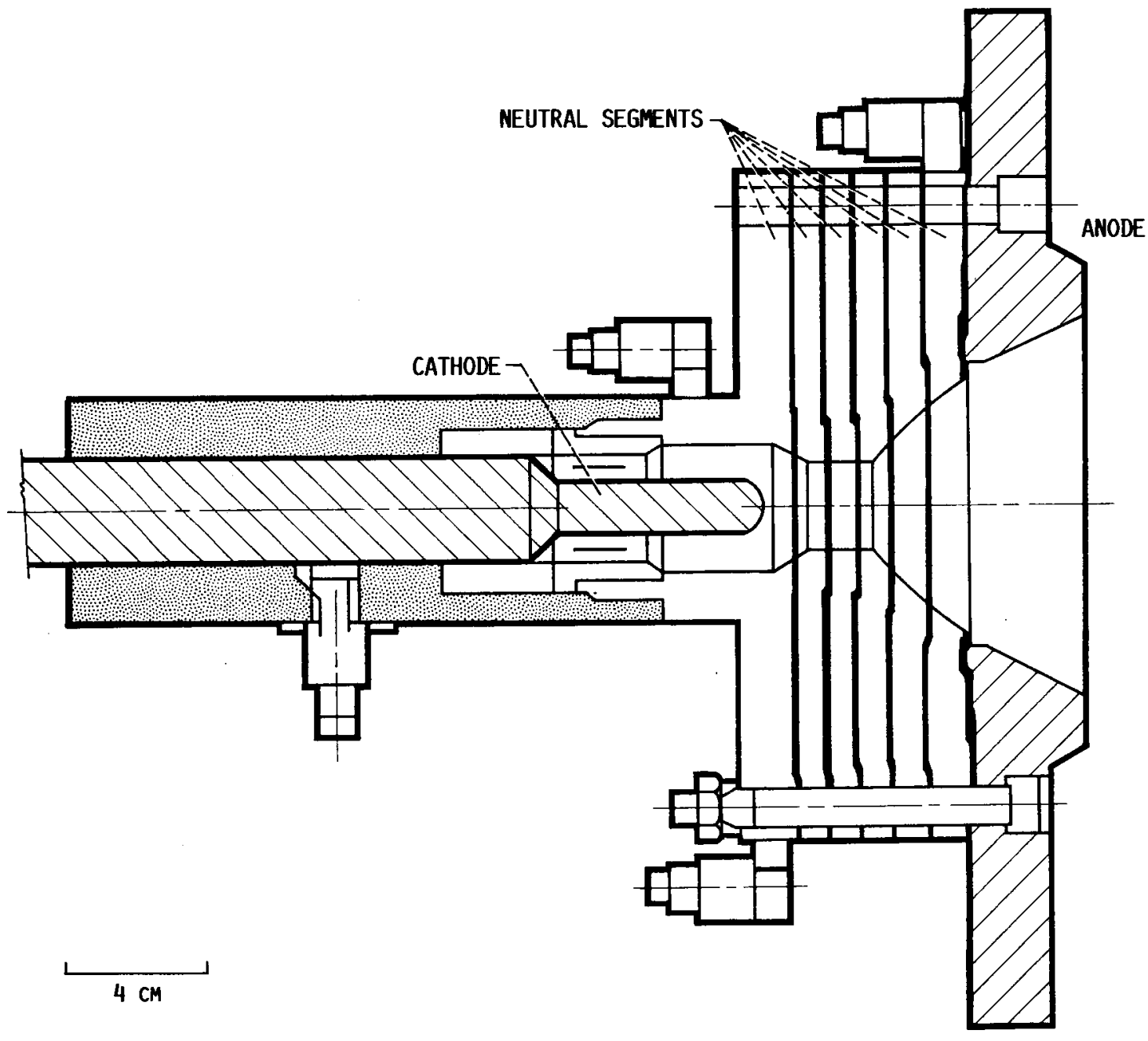

FIGURE 6. - UNIVERSITY OF STUTTGART SELF-FIELD THRUSTER. 


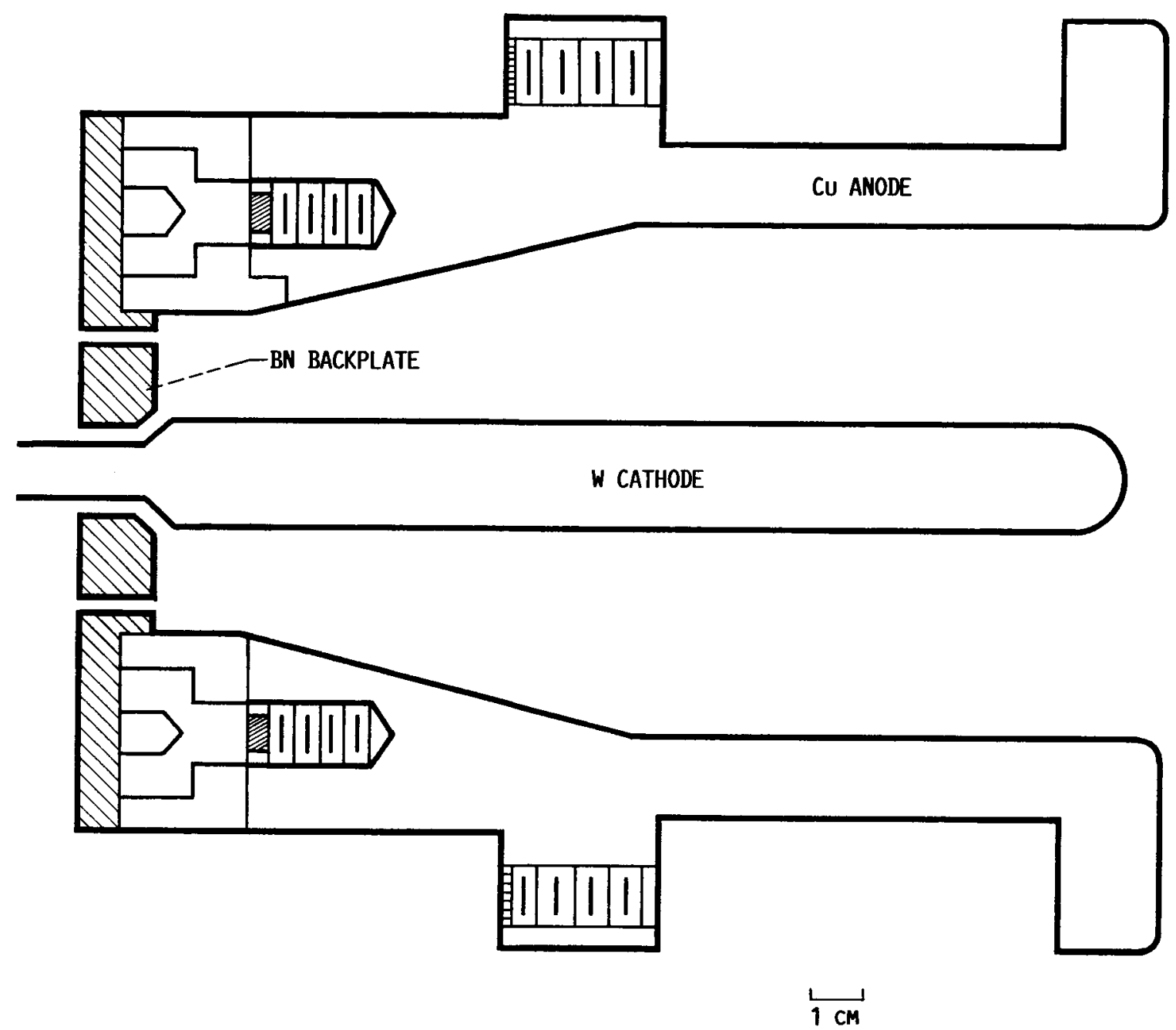

FIGURE 7. - PRINCETON UNIVERSITY QUASI-STEADY-STATE THRUSTER. 


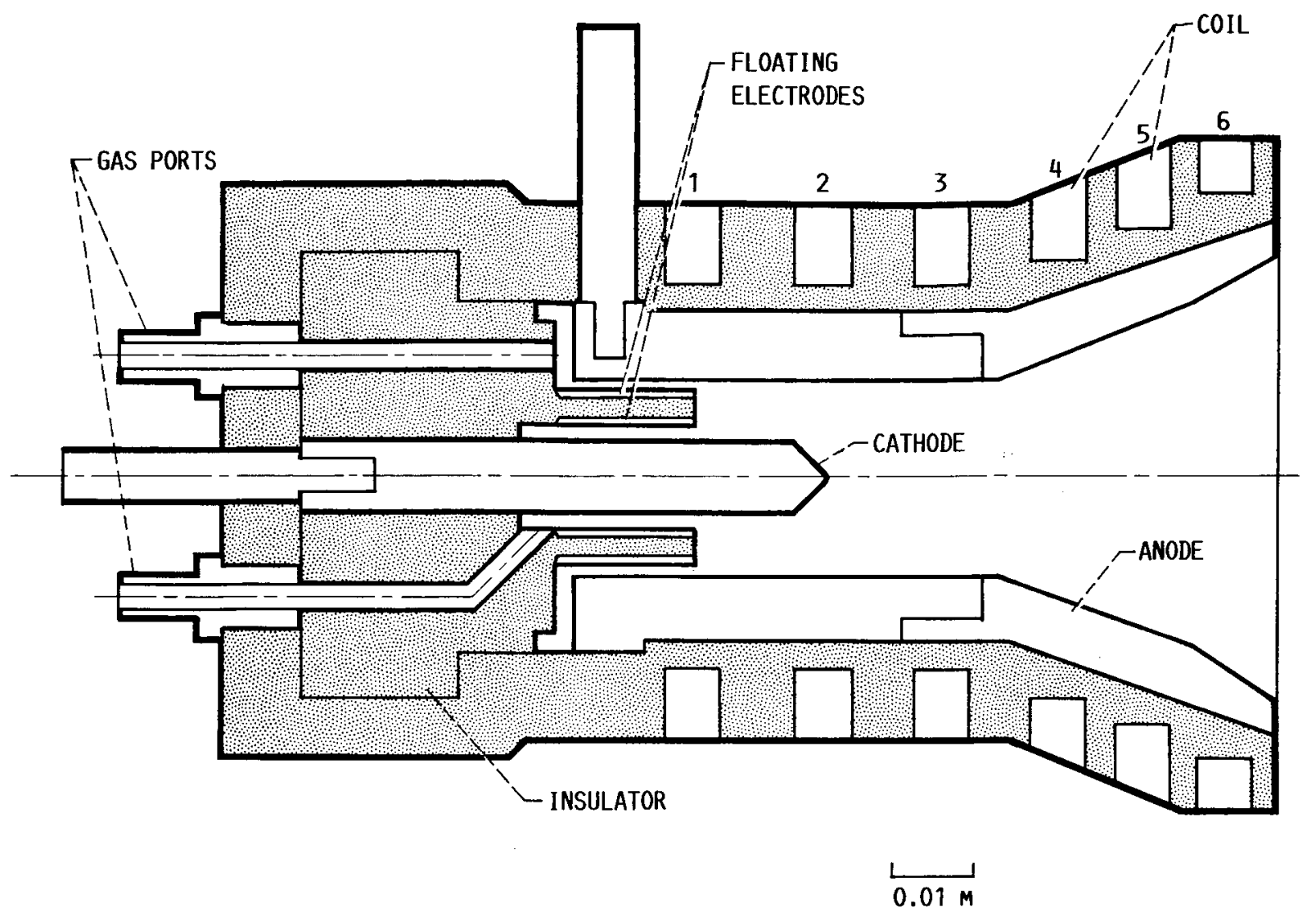

FIGURE 8. - APPLIED-FIELD QUASI-STEADY-STATE THRUSTER. (OSAKA UNIVERSITY.)

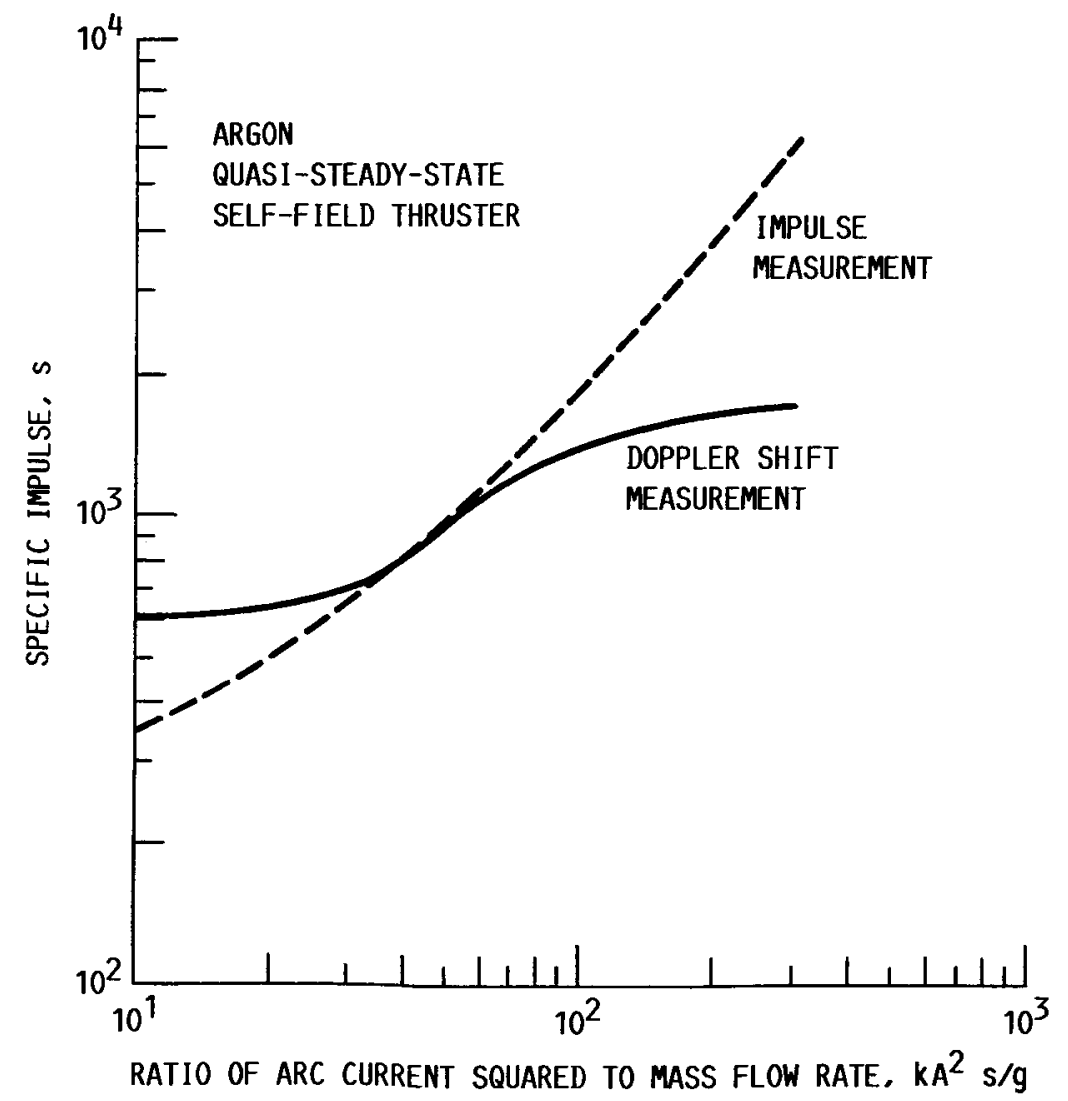

FIGURE 9. - COMPARISON OF PERFORMANCE BY IMPULSE BALANCE AND DOPPLER-SHIFT MEASUREMENT. (REF. 14.) 


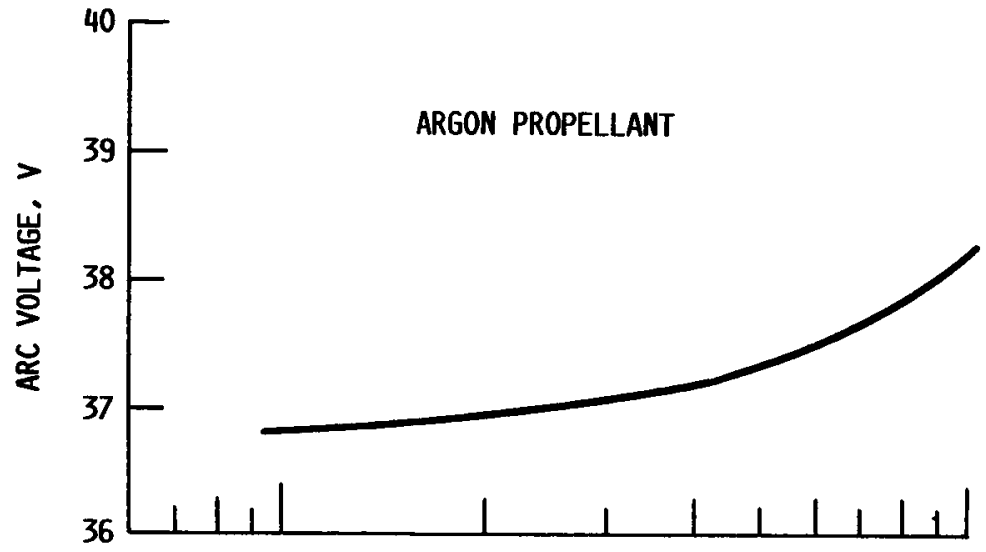

(a) ARC VOLTAGE.

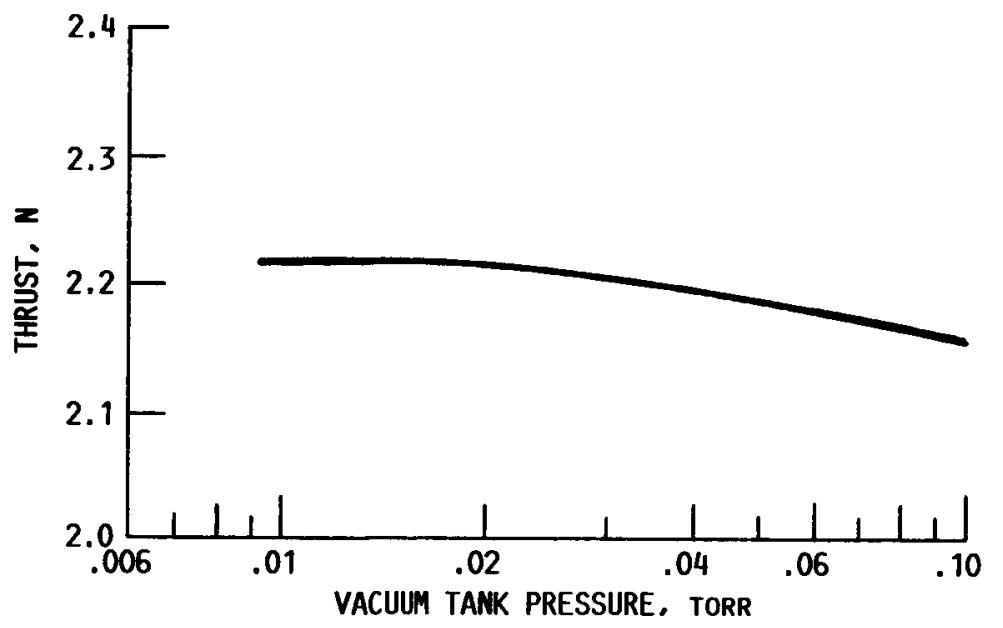

(b) THRUST.

FIGURE 10. - EFFECT OF VACUUM TANK PRESSURE ON PERFORMANCE OF A STEADY-STATE, SELF-FIELD THRUSTER.

(REF. 24.) 


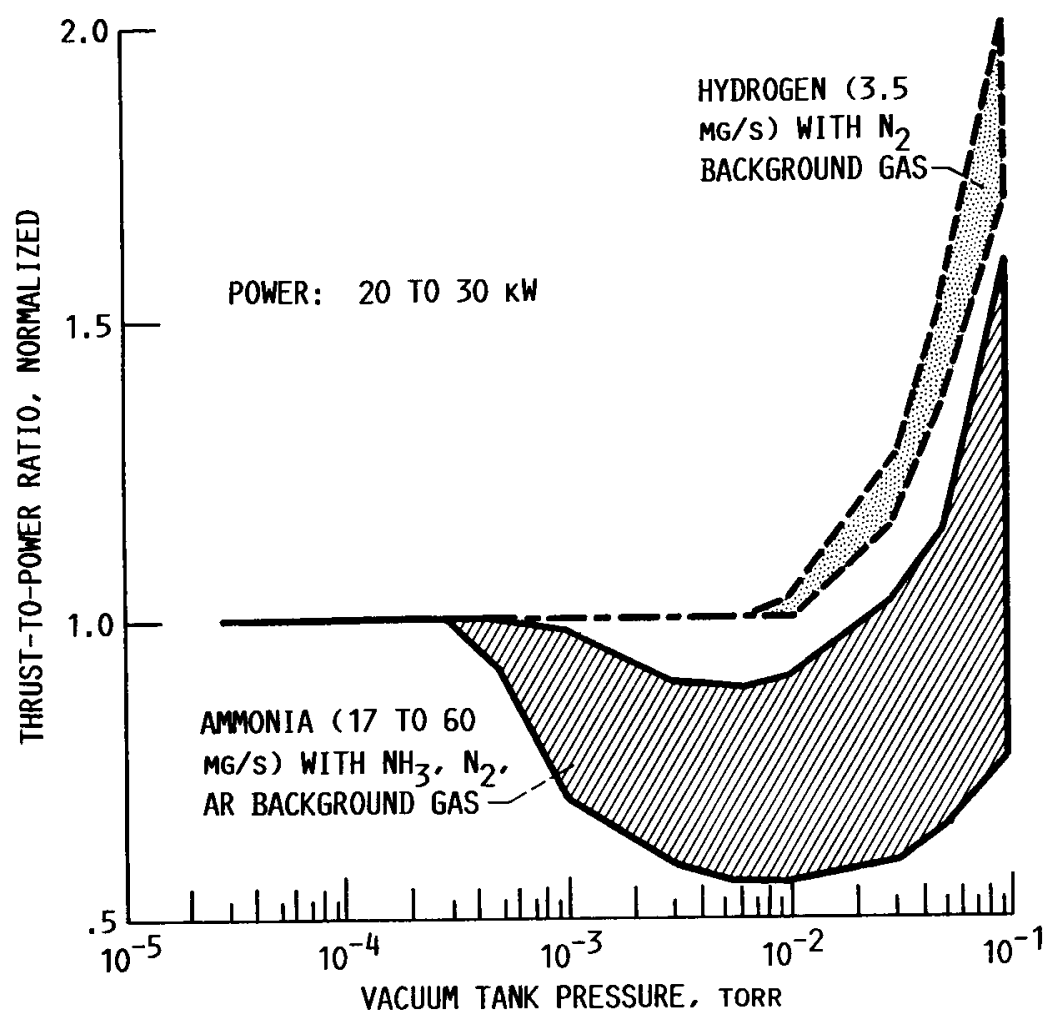

FIGURE 11. - EFFECT OF VACUUM TANK PRESSURE ON PERFORMANCE OF APPLIED-FIELD THRUSTERS. (REFS. 31 AND 36.)

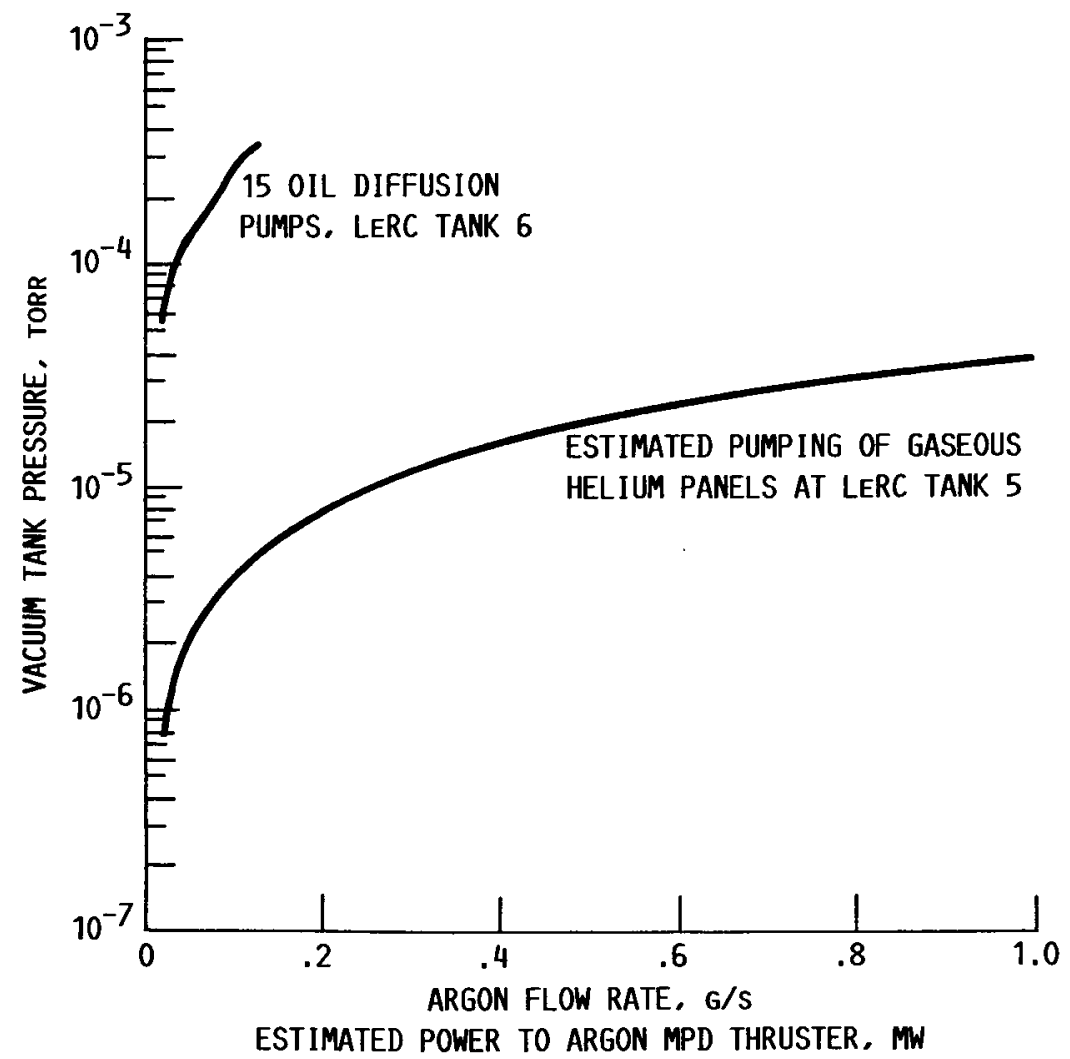

FIGURE 12. - NASA LEWIS VACUUM FACILITY PUMPING CAPABILITY FOR AN MPD THRUSTER TEST-STAND. 
APPROXIMATE POWER RANGES

-0.01 TO $0.1 \mathrm{MW} \rightarrow-0.1$ TO $1 \mathrm{MW} \rightarrow-1$ TO $10 \mathrm{MW} \rightarrow$

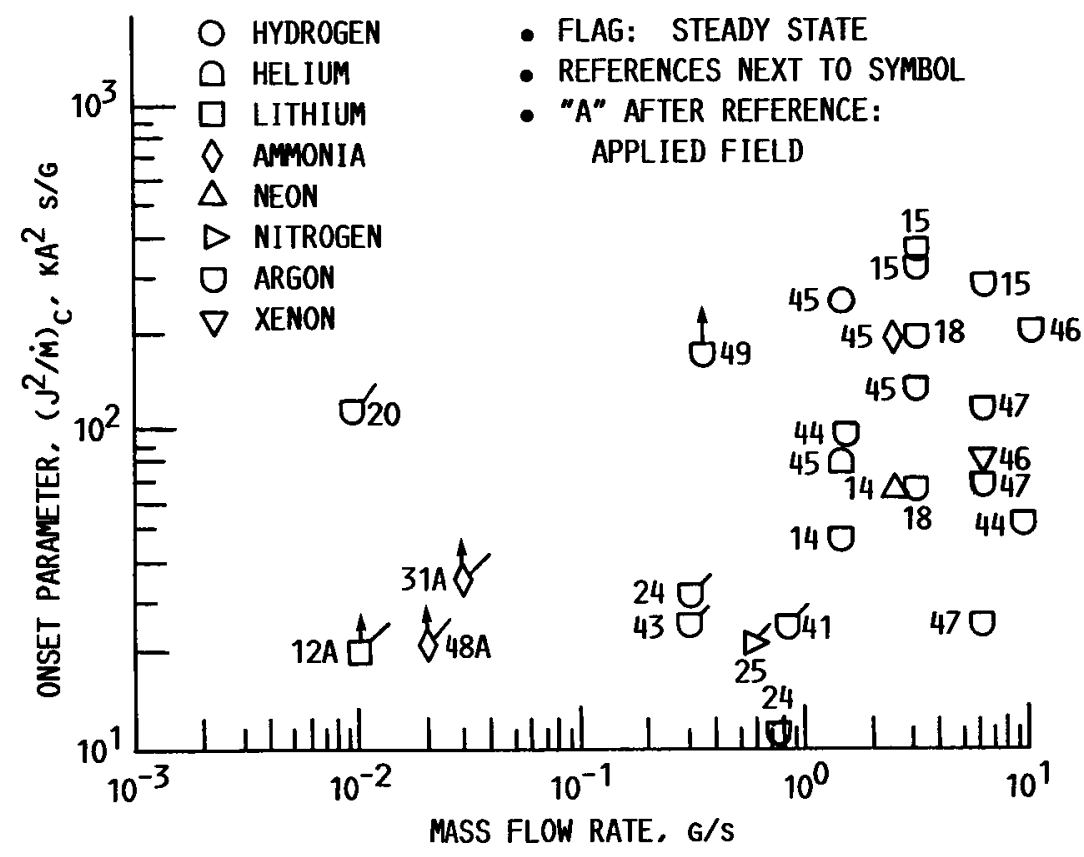

FIGURE 13. - ONSET PARAMETER VERSUS MASS FLOW RATE.

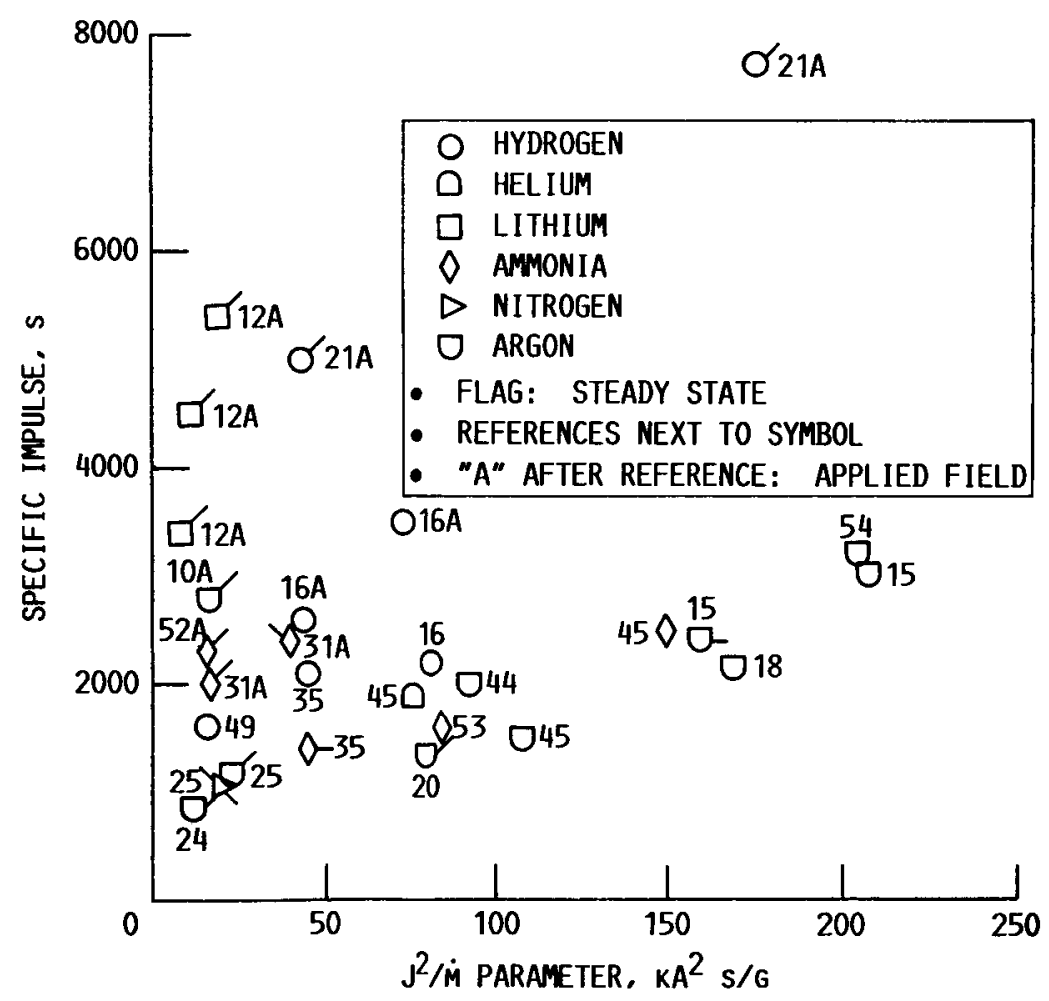

FIGURE 14. - SPECIFIC IMPULSE VERSUS $J^{2} / \dot{m}$. 


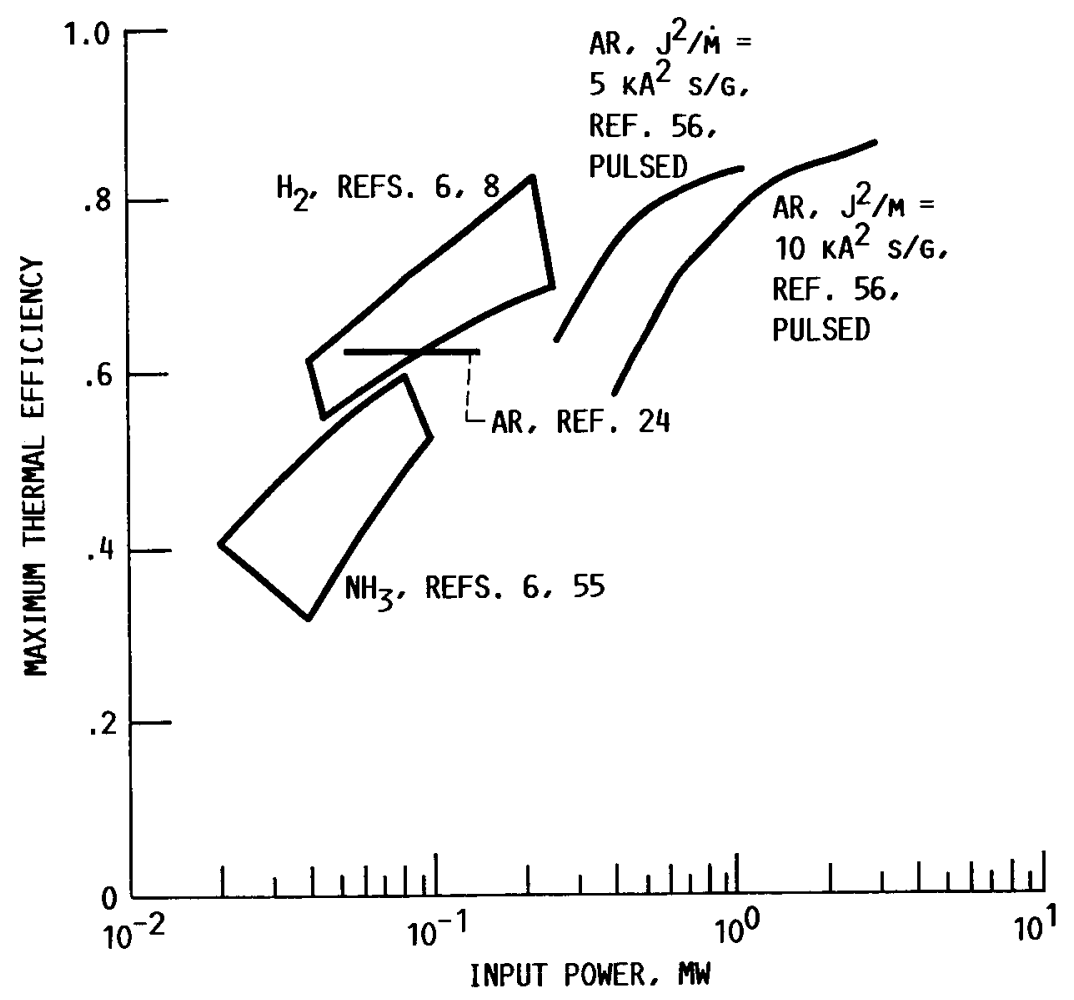

FIGURE 15. - VARIATION OF THERMAL EFFICIENCY AS A FUNCTION OF INPUT POWER.

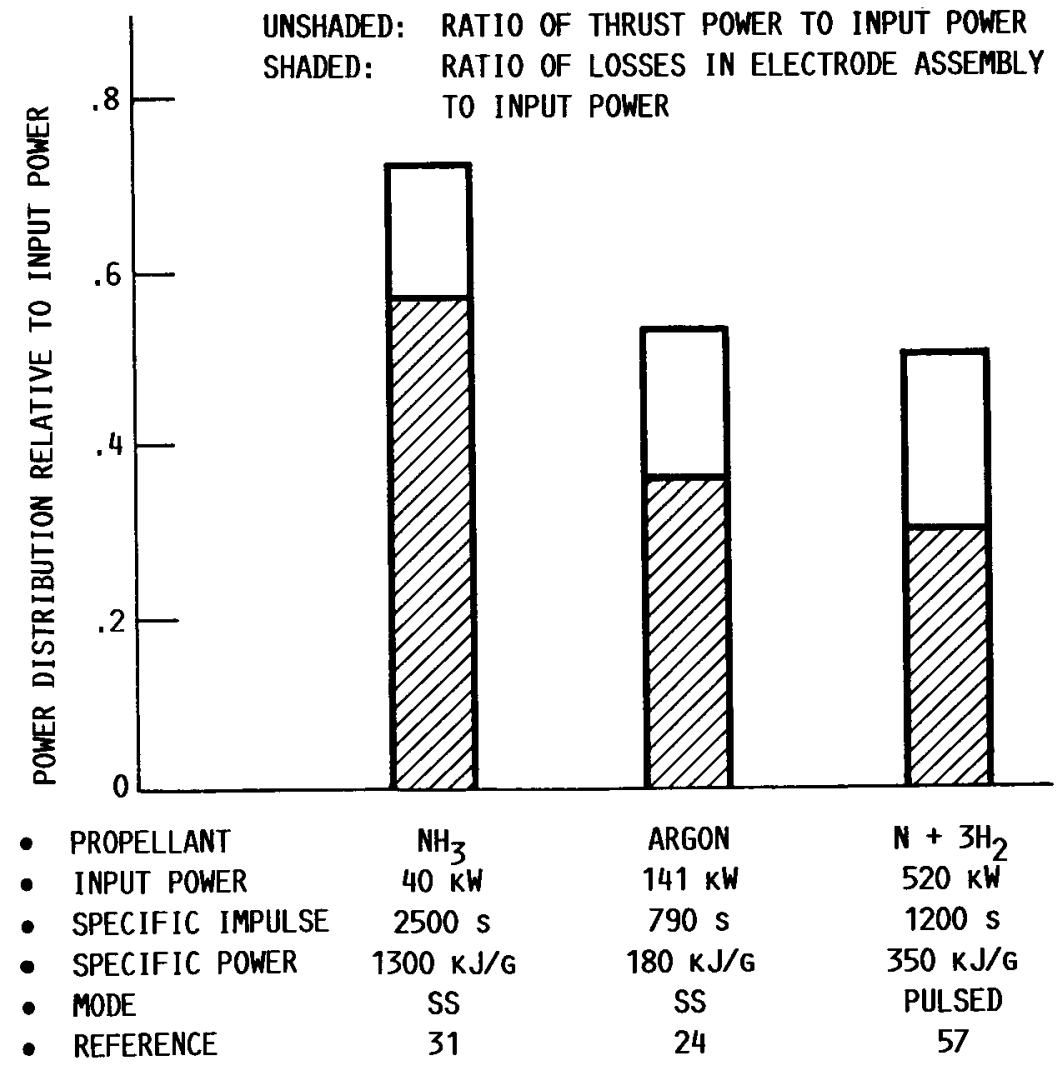

FIGURE 16. - MPD THRUSTER POWER DISTRIBUTION. 

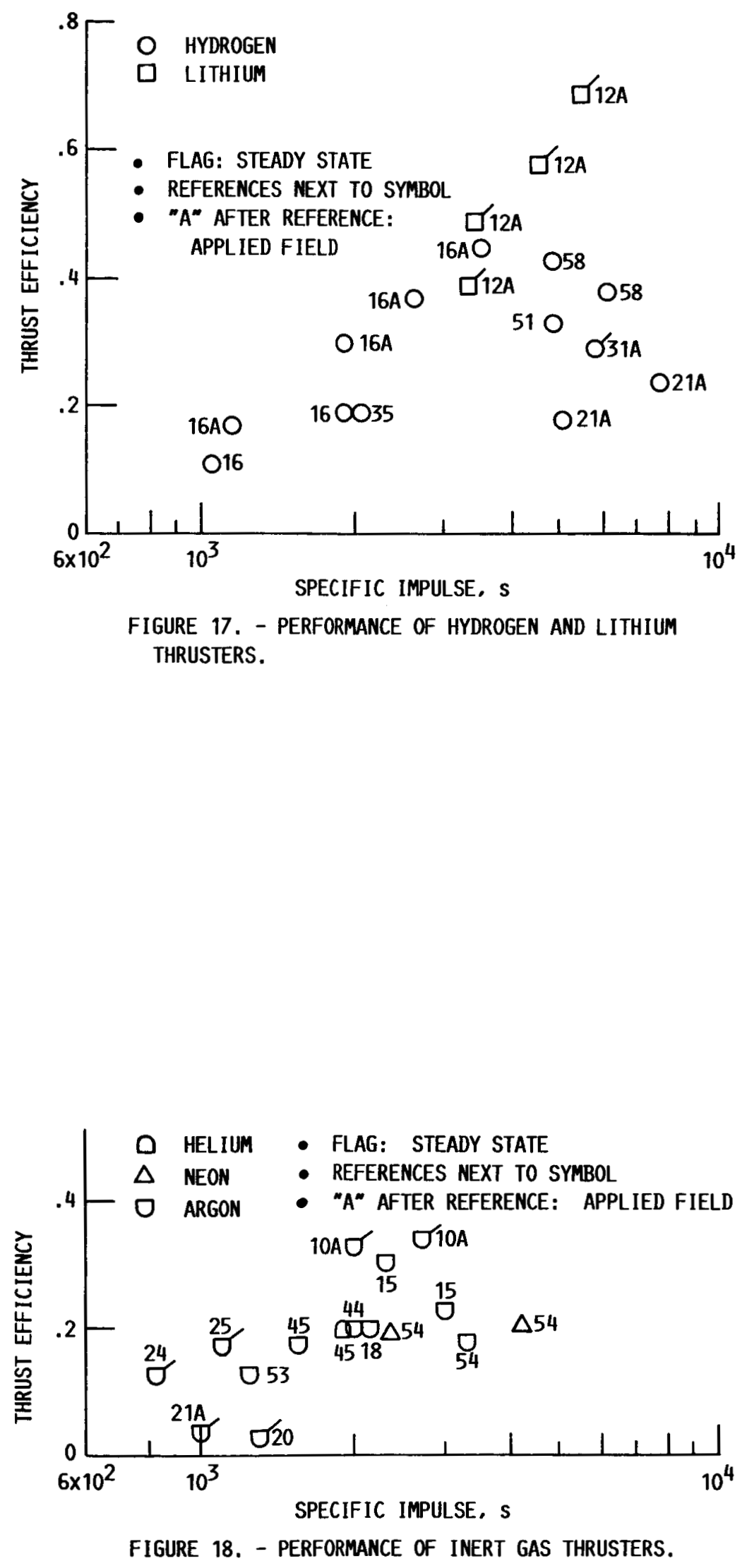


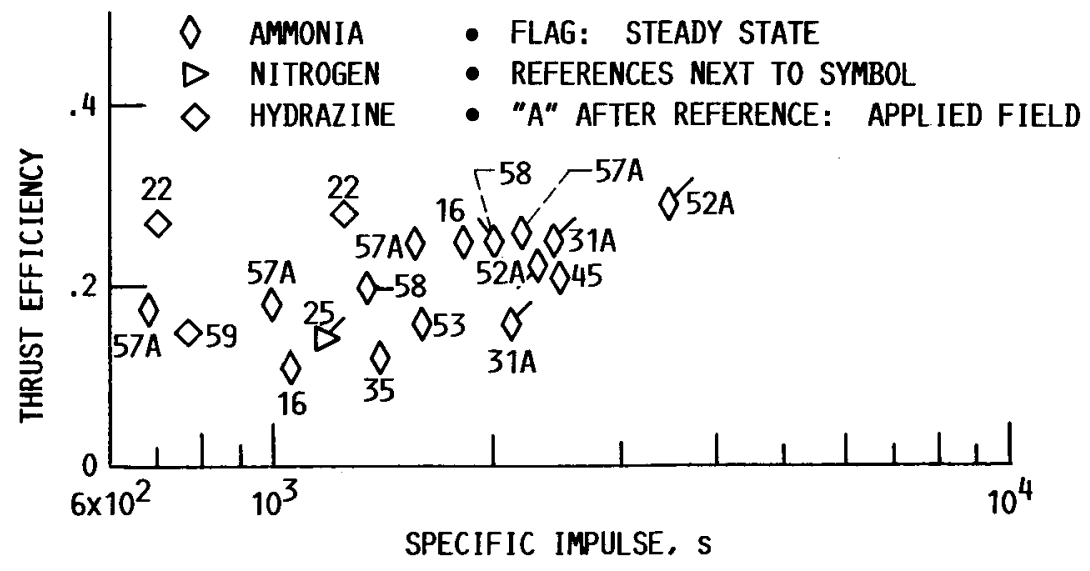

FIGURE 19. - PERFORMANCE OF PROPELLANTS CONTAINING NITROGEN.

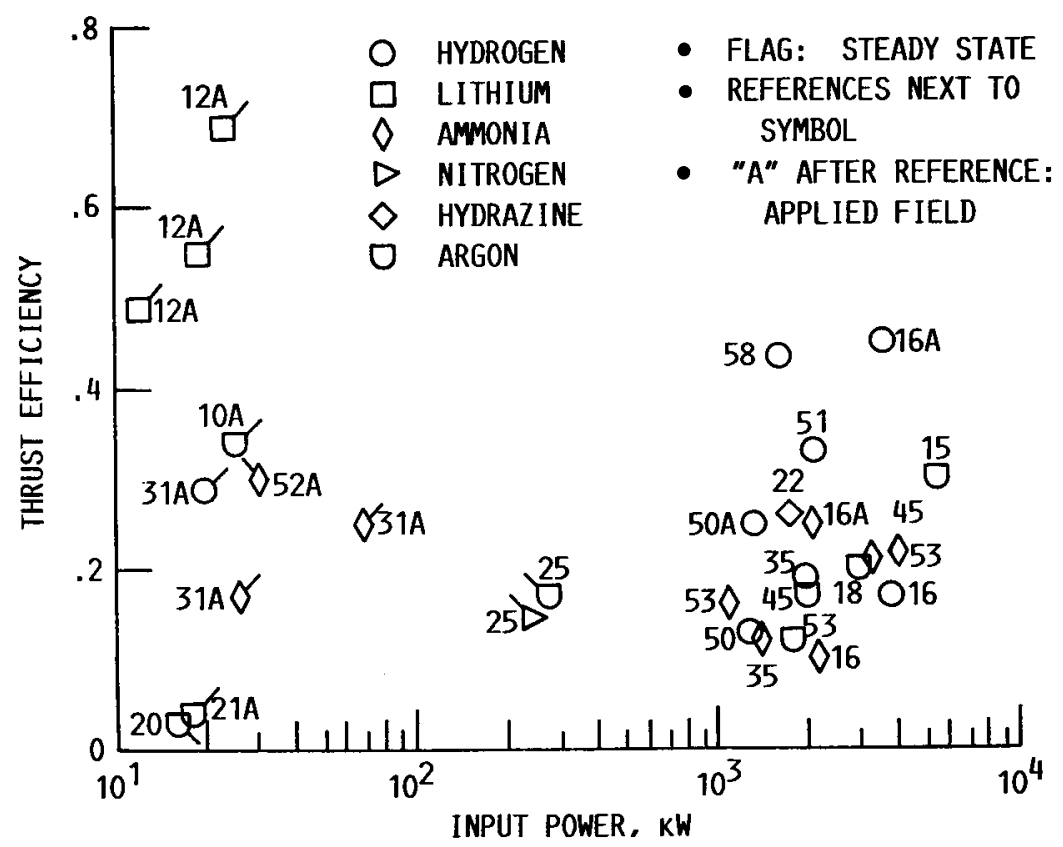

FIGURE 20. - THRUST EFFICIENCY AS A FUNCTION OF POWER AND PROPELLANT. 


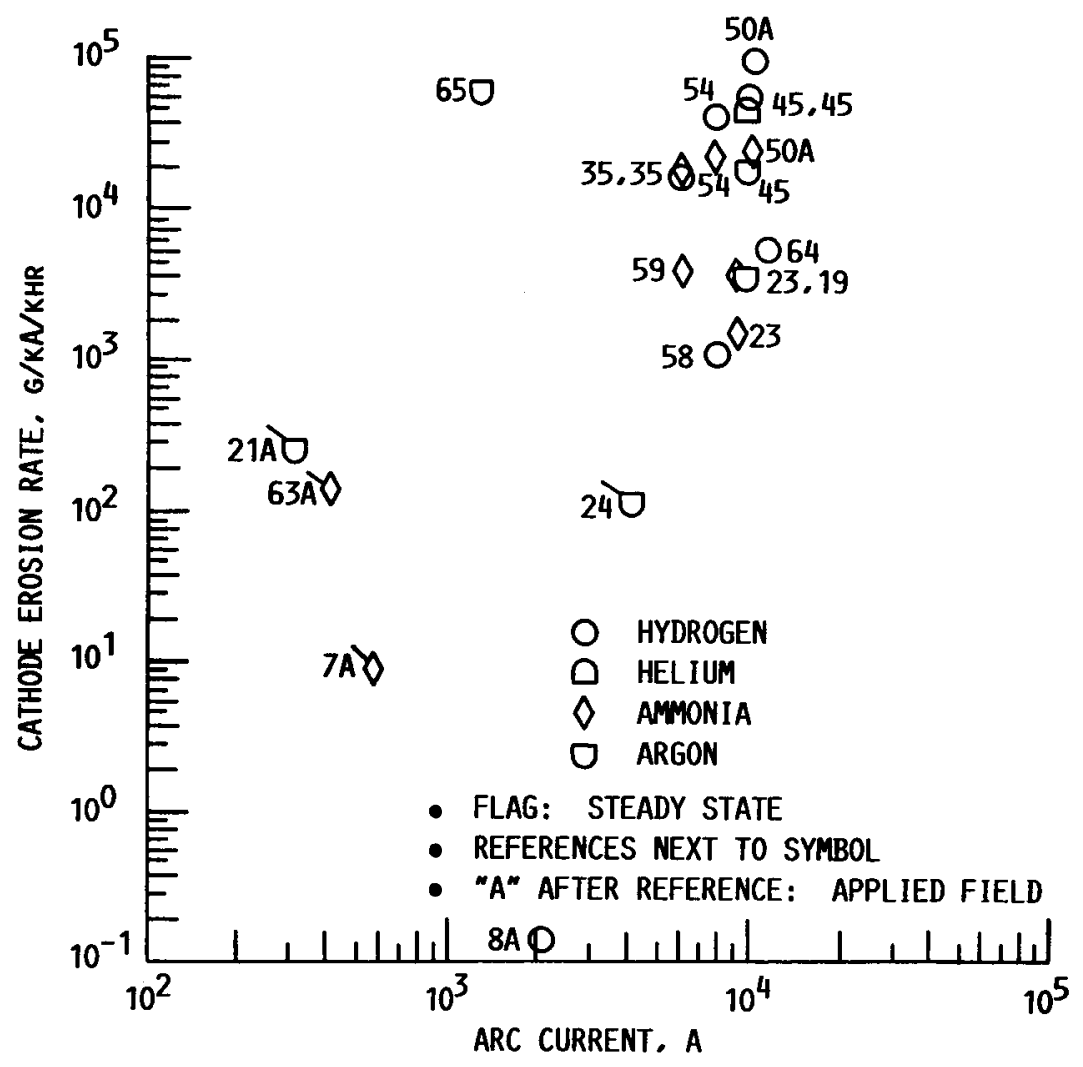

FIGURE 21. - CATHODE EROSION RATES. 


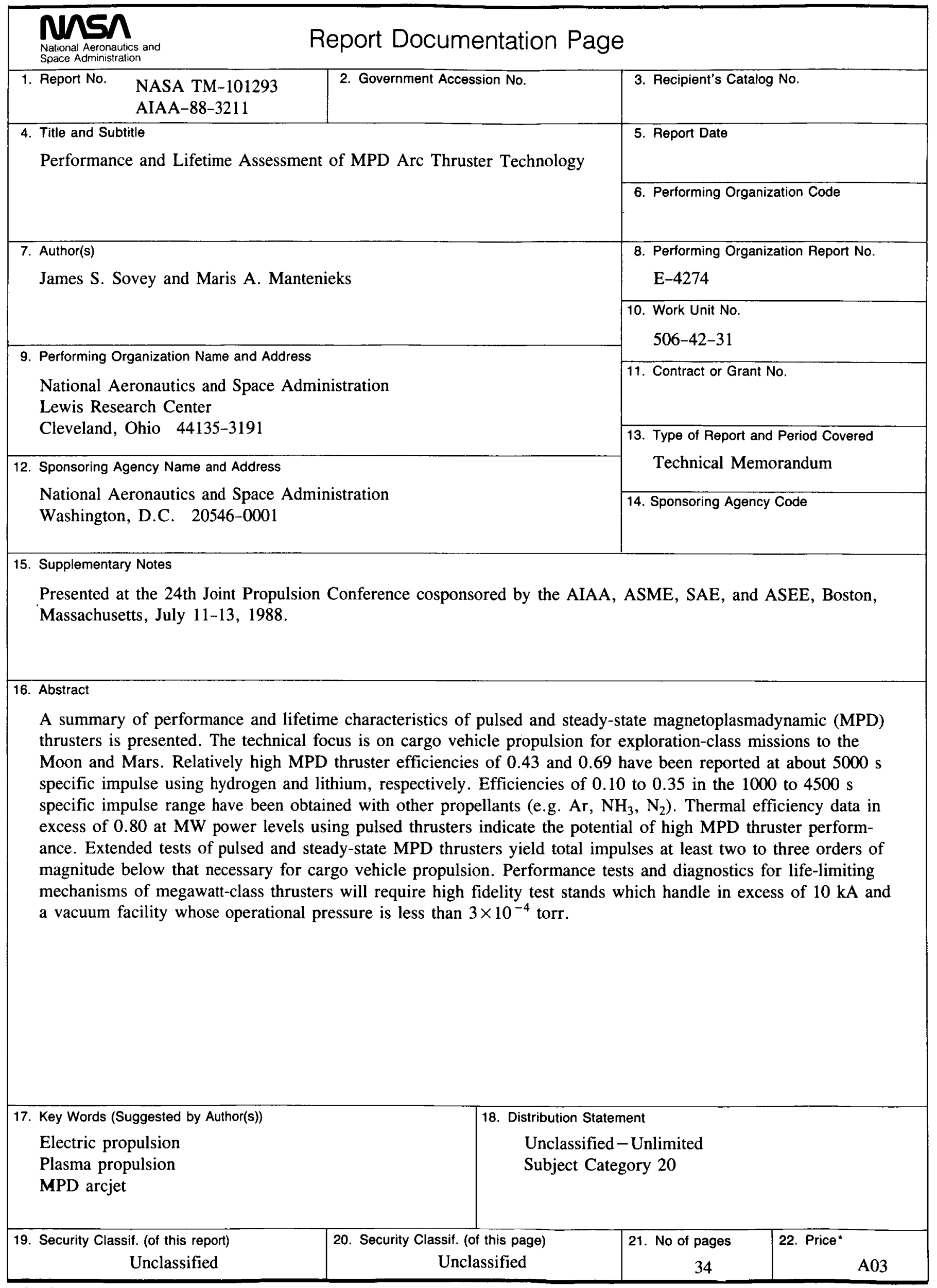

